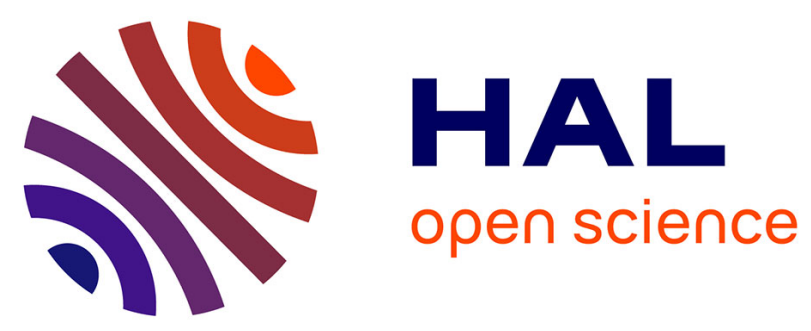

\title{
Some remarks on computational approaches towards sustainable complex agri-food systems
}

\author{
Nathalie Perrot, Hugo de Vries, Evelyne Lutton, Harald G. J. van Mil, \\ Mechthild Donner, Alberto Tonda, Sophie Martin, Isabelle Alvarez, Paul \\ Bourgine, Erik van Der Linden, et al.
}

\section{To cite this version:}

Nathalie Perrot, Hugo de Vries, Evelyne Lutton, Harald G. J. van Mil, Mechthild Donner, et al.. Some remarks on computational approaches towards sustainable complex agri-food systems. Trends in Food Science and Technology, 2016, 48, pp.88-101. 10.1016/j.tifs.2015.10.003 . hal-01269357

\section{HAL Id: hal-01269357 \\ https://hal.science/hal-01269357}

Submitted on 28 May 2020

HAL is a multi-disciplinary open access archive for the deposit and dissemination of scientific research documents, whether they are published or not. The documents may come from teaching and research institutions in France or abroad, or from public or private research centers.
L'archive ouverte pluridisciplinaire HAL, est destinée au dépôt et à la diffusion de documents scientifiques de niveau recherche, publiés ou non, émanant des établissements d'enseignement et de recherche français ou étrangers, des laboratoires publics ou privés. 


\section{Accepted Manuscript}

Nathalie Perrot, Hugo De Vries, Evelyne Lutton, Harald G.J. van Mil, Mechthild Donner, Alberto Tonda, Sophie Martin, Isabelle Alvarez, Paul Bourgine, Erik van der Linden, Monique A.V. Axelos

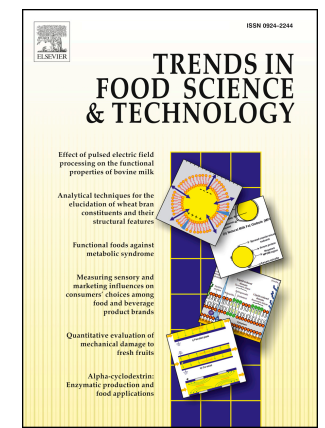

PII:

S0924-2244(15)00218-6

DOI:

10.1016/j.tifs.2015.10.003

Reference: TIFS 1710

To appear in: Trends in Food Science \& Technology

Received Date: 7 April 2014

Revised Date: 15 September 2015

Accepted Date: 3 October 2015

Please cite this article as: Perrot, N., De Vries, H., Lutton, E., van Mil, H.G.J., Donner, M., Tonda, A., Martin, S., Alvarez, I., Bourgine, P., van der Linden, E., Axelos, M.A.V., Trends in Food Science \& Technology (2015), doi: 10.1016/j.tifs.2015.10.003.

This is a PDF file of an unedited manuscript that has been accepted for publication. As a service to our customers we are providing this early version of the manuscript. The manuscript will undergo copyediting, typesetting, and review of the resulting proof before it is published in its final form. Please note that during the production process errors may be discovered which could affect the content, and all legal disclaimers that apply to the journal pertain. 


\section{SOME REMARKS ON COMPUTATIONAL APPROACHES TOWARDS SUSTAINABLE COMPLEX AGRI-FOOD SYSTEMS}

\section{Structured Abstract}

\section{Background}

Agri-food is one of the most important sectors of the industry in Europe and potentially a major contributor to the global warming. Sustainability issues in this context pose a huge challenge for several reasons: the variety of considered scales, the number of disciplines involved, the uncertainties, the out-of-equilibrium states, the complex quantitative and qualitative factors, the normative issues and the availability of data. Although important insight and breakthroughs have been attained in different scientific domains, an overarching and integrated analysis of these complex problems have yet to be realized.

\section{Scope and Approach}

This context creates huge opportunities for research in interaction with mathematical programming, integrative models and decision-support tools. The paper propose a computational viewpoint including questions of holistic approach, multiscale reconstruction and optimization. Some directions are discussed.

\section{Key Findings and Conclusions}

Several research questions based on a mathematical programming framework are emerging: how can such a framework manage uncertainty, cope with complex qualitative and quantitative information essential for social and environmental considerations, encompass diverse scales in space and time, cope with a multivariable dynamic environment and with scarcity of data. Moreover, how can it deal with different perspectives, types of models, research goals and data produced by conceptually disjoint scientific disciplines, ranging from physics and physiology to sociology and ethics? Building models is essential, but highly difficult; it will need a strong iterative interaction combining computational intensive methods, formal reasoning and the experts of the different fields. Some future research directions are proposed, involving all those dimensions: mathematical resilience, humanmachine interactive learning and optimization techniques.

\section{Keywords}

Agri-food systems, sustainability, multiscale modeling, optimization, resilience, human-machine

interactive learning. 


\section{SOME REMARKS ON COMPUTATIONAL APPROACHES TOWARDS SUSTAINABLE COMPLEX AGRI-FOOD SYSTEMS}

\section{Authors}

Nathalie Perrot ${ }^{\mathrm{a}, c^{* 1}}$, Hugo De Vries ${ }^{\mathrm{b}}$, Evelyne Lutton ${ }^{\mathrm{a}, \mathrm{c}}$, Harald G.J. van Mil ${ }^{\mathrm{h}}$, , Mechthild Donner ${ }^{\mathrm{g}}$, Alberto Tonda ${ }^{a, c}$, Sophie Martin ${ }^{c, d}$, Isabelle Alvarez ${ }^{\mathrm{d}, \mathrm{e}}$, Paul Bourgine $^{\mathrm{c}}$, Erik van der Linden ${ }^{\mathrm{h}, \mathrm{i}}$, Monique A.V. Axelos ${ }^{\mathrm{f}}$

\section{Affiliations}

a INRA, UMR782 Génie et Microbiologie des Procédés Alimentaires, F-78850 Thiverval-Grignon, France (Tel.: +33 1-30-81-53-79; fax : +331-30-81-55-97; email: nathalie.perrot@grignon.inra.fr, evelyne.lutton@grignon.inra.fr, alberto.tonda@grignon.inra.fr )

b INRA, UMR1208 Ingénierie des Agropolymères et Technologies Emergentes, F-34060 Montpellier, France (Tél. : +33 4996128 31) devries@supagro.inra.fr,

${ }^{\mathrm{C}}$ ISCPIF (Institut des Systèmes complexes Paris Ile de France, 133 rue Nationale - F 75013 Paris (Tél. +33145526411- Fax : +33145526455)

d IRSTEA, LISC. 24 avenue des Landais, BP5 008563172 Aubière, France, (Tel/fax: +334 734406 00, sophie.martin@irstea.fr, isabelle.alvarez@irstea.fr)

e UPMC, Lip6, 104 av. du Président Kennedy, 75016 Paris, France, (Tel/fax: +33 1442787 38)

${ }^{f}$ INRA, UR1268 Biopolymères Interactions et Assemblages, F-44300 Nantes, France (Tel: +33 (0) 240 675031 : email : Monique.Axelos@nantes.inra.fr)

${ }^{1}$ Corresponding author: Nathalie Perrot Tel.: +33 1-30-81-53-79; fax : +331-30-81-55-97; email: nathalie.perrot@grignon.inra.fr) 
${ }^{\mathrm{g}}$ Montpellier SupAgro, UMR MOISA, 2 Place Pierre Viala, 34060 Montpellier Cedex 02, France (Tél. : +33499612831; email : devries@supagro.inra.fr, mechthild.donner@supagro.inra.fr)

h TI Food and Nutrition, Nieuwe Kanaal 9A, 6709 PA Wageningen, The Netherlands, irede@vanmil.net, vanderlinden@tifn.nl

'Laboratory of Physics and Physical Chemistry of Foods, Wageningen University and Research Center, Bornse Weilanden 9 (building 118) 6708 WG Wageningen, The Netherlands. e-mail: erik.vanderlinden@wur.nl

\section{Abstract}

Agri-food is one of the most important sectors of the industry in Europe. Sustainability issues in this context pose a huge challenge. This paper gives a computational viewpoint on this problematic in order to develop a more holistic approach, a link between different scales and clear insights in the complexity of agri-food systems. This creates huge opportunities for research in mathematical programming, integrative models and decision-support tools. In this paper we outline some future research directions on mathematical resilience, human-machine interactive learning and optimization techniques.

\section{Keywords}

Agri-food systems, sustainability, multiscale modeling, computing complex system, decision support system, optimization, resilience, human expertise, interactive learning.

\section{Introduction}

Food (Lehmann, Reiche \& Schiefer, 2012) is one of the most important sectors of the industry (CIAA 2009), encompassing chemicals, agriculture, feed, food processing and trade, retail and consumer 
sectors. Production and consumption of food is the major contributor to the global warming potential in Europe (31\%), taking into account all products required by the society. Amongst food products, meat and dairy have been identified as the main contributors to the global environmental impact, with a share of up to $12 \%$ in the case of meat, and up to $4 \%$ in the case of dairy products.

The food industry is fully aware that environmental performances of products and processes need to be improved in the full production-till-consumption chain ${ }^{2}$. In addition, the consumer's needs should be met for food safety, health, convenience, lifestyle and product choice; and at the same time, commercial and financial benefits of the entire value chain must be assured in order to retain competitiveness. The problem to solve is particularly complex, since the management of the sustainability approach requires a multi-scale, multi-disciplinary and multi-factorial approach.

Sustainability starts at the farm level with the application of a large set of good farming practices, the preservation of natural resources and biodiversity, the development of specialized skills and capabilities, as well as the respect of farmer's choices in a given social and economic environment.

Subsequently, the transformation phase for biomass must be considered. Processes need to use these natural resources in a highly efficient way, developing bio-refineries to transform waste in byproducts, and reconsidering the supply chain, currently still organized in a "product chain". Energy saving and water recycling are of course the major challenges in this step: they require development of new technologies through investments in research, increased awareness, especially crucial for SMEs (small and medium enterprises) to integrate innovation and a strong support from regional and (inter-)national policies. The volume of packaging has considerably increased in response to consumer demands for safety and affordability of products; its reduction is a tremendous challenge in the wider context of reducing household food waste while maintaining food quality.

\footnotetext{
${ }^{2}$ For further details, see http://ec.europa.eu/research/bioeconomy/pdf/201202 innovating sustainable growth en.pdf http://etp.fooddrinkeurope.eu/documents/2012/SRIA 2012/SRIA ETP Food4Life 2012.pdf 
The third part of the equation concerns logistics, in particular when dealing with perishable products.

In a world which did not take into account the environmental balance for a long time, road transportation became the major delivery means, with a considerable impact on greenhouse gas emission. Solutions exist, but require strong initiatives at a pan European level from politics, industry, research institutions and NGOs.

Finally, consumers should not be overlooked, because they play a major role in the sustainability of the food chain through their home practices, purchasing decisions, trade of shares and stocks, cultural and normative diverse background and requirements, etc.

In this context, creativity to reach breakthrough innovations on the one hand, and efficiency and optimization on the other hand, are crucial to obtain sustainable solutions: appropriate strategic visions, organization, transparency and control, assure safety and quality of novel products and ingredients (Lehmann, Reiche \& Schiefer, 2012), as well as accessibility and affordability of food. Reaching these objectives requires multi-scale approaches, starting from the nano-scale for products and their ingredients, up to the $\mathrm{km}$-scale for regional and global management issues, including organization and control of factories and food chains.

At each scale, one may observe a diversity of complex products and networks of organizations. In highly developed countries, production is characterized by very different types of enterprises, ranging from single-product manufacturers to generalists providing diverse products, technologies, services and logistics (Lehmann, Reiche \& Schiefer, 2012). Production organization ranges from local to global, from farm to fork and beyond, from fast-foods to high-end restaurants, from laboratories to factories and supermarkets, from supply to demand and from single entities to full networks. Historically, agriculture and the linked manufacturing industry are considered to be independent sectors (Thompson \& Scoones 2009) (Reilly \& Willenbockel 2010); this holds today as well for the biobased non-food sector. If we consider full food value chains as multi-input and multi-output 
networks (or systems), it is noticeable how they are still poorly developed, when compared to the specific needs of consumers, society and environment at large; but since this vision of food chains has rarely been taken into account, numerous new opportunities and more sustainable solutions have yet to be considered.

In order to achieve sustainable approaches, different strategies can be developed by enterprises and societies. These strategies and their underlying models, however, might be synergic, neutral or in conflict with each other. It is thus crucial to carefully choose the strategies to follow, since these decisions are laden with moral, aesthetical and socio-economical values. Many heterogeneous factors, some being dynamical like zeitgeist, availability of information and perceived pressures, are to be taken into account when creating new legislation on sustainability. Normative dimensions of agri-food problems have the property of being heterogeneous, and can even be self-organising (see section 2.1). Indeed, we may view the normative dimensions involved as a stand-alone complex system, one that influences in turn the development of sustainability in many areas. This problem calls for a systematic approach on fair decisions, able to respect different moral, aesthetic and socialeconomical constraints (e.g. see Rawls, 1999).

A transition towards a bio-based society, while maintaining a viable planet and ethically wellaccepted conditions, requires addressing various opportunities and devising appropriate solutions.

This paper gives a computational viewpoint and guidelines in order to develop (1) a more holistic approach, (2) a link between different scales and (3) clear insights in the complexity of agri-food systems. The rest of the paper is organized as follows: Section 2 considers the most relevant questions in a complex system approach for sustainable food systems. Section 3 reviews possible research directions, while Section 4 details three sources of inspiration for new approaches in the food domain. Sections 5 and 6 draw the conclusions and sketch high-level perspectives for the future. 

bottlenecks

\subsection{A holistic approach: an introduction to complex system science}

A holistic approach can be characterized as the process of integrating, through interdisciplinarity and provides a means to answer questions about inherent linkages and feedbacks within social-ecological systems, such as sustainable fisheries (Miller et al., 2010) and agricultural value chains (Higgins et al., 2010). Several dimensions should be taken into account: spatial, organizational, temporal scales, and the correlated rates of change; spatial distributions of variables, their scaling, and feedback loops have to be considered, as well as their interpretation within the relevant scientific disciplines.

This holistic approach cannot be managed "manually" $a b$ initio and there is a clear need for decisionsupport tools based on different fields of computer science (applied mathematics, artificial intelligence, optimization), see sub-section 2.3 below. One of the most crucial tasks related to the development of such support tools is the design of models (Perrot et al., 2011, Charpentier, 2010, Trystram, 2012). Modeling complex systems through a holistic approach is an iterative activity that requires knowledge and comprehension of scientific facts, expert skills and sensory assessments, and relies upon methods allow for cross-overs with new fields in computer science.

CSS (complex system science) makes it possible to cope with the expanding boundaries of complex adaptability in agri-food systems; there is an increasing focus on interacting economic, social and environmental goals. Emergence of properties from these dynamical interactions should be studied. 
137 The 2012-2020 roadmap defined the science of complex systems ${ }^{3}$ as distinct from any other

138 particular science, because it focuses on the methods of reconstructing the dynamics of

139 heterogeneous systems across traditional domains.

140 Systems can exhibit many properties that make them appear complicated or complex. These include:

141 - heterogeneous parts, e.g. a city, agriculture and the climate;

142 - complicated transition laws, e.g. agriculture and climate transitions;

143 - unexpected or unpredictable emergence, e.g. chemical systems, accidents;

144 - sensitive dependence on initial conditions, e.g. weather systems, investments;

145 - path-dependent dynamics, e.g. international relations, regional subventions;

146 - network connectivity and multiple subsystem dependencies, e.g. ecosystems, multiple

147 industrial sectors;

148 - dynamics that emerge from interactions of autonomous agents, e.g. agriculture, traders;

149 - self-organization into new structures or behavioral patterns, non-equilibrium and far-from

150 equilibrium dynamics, adaptation to changing environments, e.g. biological systems, manufacturing 151 design.

152 Such properties are vertical, in the sense that they cut across disciplines which are researched

153 horizontally in greater depth, based on the assumption that they can be treated in isolation (to a

154 greater or lesser extent) by other domains. Economists, sociologists, food engineers, plant scientists,

155 etc. traditionally tend to work in isolation from each other, while the science of complex systems

156 aims at using a new methodological perspective. The transdisciplinary nature of CSS makes it unique

157 because it strives to combine the methods, knowledge and theory of other disciplines. The complex

158 system methodology starts from heterogeneous data and knowledge (Figure 1). The objective is to

159 produce an augmented phenomenology where $\Delta$, the statistical difference from observation, is as

${ }^{3}$ http://roadmaps.csregistry.org/tikiindex.php?page=The+science+of+complex+systems\&structure=european $r$ oadmap 
small as possible but taking care of the danger of overfitting. For example, from the data and knowledge available about the structure-function elaboration of a food product, a phenomenological model encompassing the impact of a change in raw material usage on the food structure, its function, and consumer acceptance, can be created. Coupled to a model expressing the link between the raw material production and the territory scale organization, an agent-based computer simulation can be built to create an augmented phenomenology for this system, spanning from the $\mathrm{km}$-scale to the nano-scale (Figure 1, bottom-center). On the basis of these simulations and knowledge availability, a model of organization covering the various scales is proposed to create another augmented phenomenology and the possibility of conceptual modeling by mathematical means (Figure 1, bottom-right), developed in more detail in (Van Mil et al., 2014).

[Figure 1 about here]

These augmented phenomenological holistic models are complex in their own right, and not always easy to interpret on a more general level, nor directly translatable to different contexts or related problems. More general models can be applied to a broader range of systems, but they lack the quantitative precision of augmented phenomenological models: thus, we need different classes of models to deal with complex problems at a deeper conceptual and abstract level. It is almost impossible to deduce models of complex systems ab initio: a good research strategy would be to start from empirical or phenomenological models, and then search for invariant structures, see (Stoutemyer, 2013) and, in a slightly different context, (Suppes, 2002). These invariant structures can then be interpreted in the light of overarching theories, or help theory construction. In order to find meaningful model structures, it becomes necessary to use more advanced mathematics and computer science, which allow different models to be mapped onto each other, and uncover the 
invariant parts (Suppes, 2002; Stoutemyer, 2013). Giving meaning to these invariant structures calls for thorough interdisciplinary knowledge of the subject and the consultation of experts (see below 3.2). Such a strategy creates interesting opportunities for fundamental mathematics and logic in the context of computer science: this fact is not yet fully realized, but it can lead to innovations very difficult to obtain otherwise. We will not explore this branch of research further in the publication but will focus more on computational methods.

We only would like to note here that augmented phenomenological models and more general models can strengthen each other in terms of research quality. As in physics, analytic models are checked by numerical simulation and vice versa. This abstract process makes it possible to gain insights that would be otherwise very difficult to reach, and shows the necessity of a pragmatic pluralistic approach, as defined by (Suppes, 2002). No matter how complex, a holistic approach should have internal checks and balances, and create a well defined link between study design, data and models of different types, precision and abstraction.

\subsection{A multi-scale approach}

A major challenge is to crossover and to connect the scales, from the resource-structure level to the territory scale, and even beyond. While individual farmers or food companies at particular locations may be our empirical focus, their options and opportunities must be understood in relation to processes interacting across scales (Thompson \& Scoones 2009), from the very local to the global ones. A pathway being pursued at one level may interact - positively or negatively - with options at another level, thus interconnections between individual, household, institution, regional clusters on one hand and (sub-)molecules, cells, plants and ecosystems on the other hand are all critical. Too often, analyses begin and end at the same scale, failing to explore larger effects. It is thus necessary 
to step out of "disciplinary boundaries", the comfort zone, which define and frame traditional analyses, in order to establish more useful interdisciplinary connections.

Problems that are non-linear in nature, cross-scale in time and space, and dynamic in character interactions, related to food and agriculture, in a dynamic world.

Nevertheless, bio-based sciences emerged from traditional experimental sciences, the latter having procedures that often to narrow down the focus in order to pose specific questions, set hypotheses, collect data and design critical tests for hypothesis rejection. The goal has been to reduce uncertainty up to the point where acceptance of an interpretation among scientific peers is essentially unanimous. A drawback of this traditional "trial \& error" approach is the limited knowledge it provides on the entire systems (Thompson \& Scoones 2009) (Walker et al., 2006).

Recent work on resilience suggests that many of the observed shifts, crises, or nonlinearities in ecological systems arise from processes and structures interacting across scales (Holling, 2001); and in fact, disruptions at different scales at the same time push the full system into another attractor more easily than a single perturbation on a single scale. For instance, resilience has been studied and extensively discussed for sustainable fisheries (Miller et al., 2010). A possible trap experts can fall into is to try to understand the single parts and, consequently, lose the global perspective of the system (Walker et al., 2006). Complexity, diversity and opportunity in complex (local) systems emerge from a handful of critical variables and processes that operate over distinctly different scales in space and time. There is a strong need for integrative frameworks that bridge disciplines and scales (Van Mil et al., 2014). 


\subsection{Decision making issues and quantitative sociodynamics}

233

234

Decision support tools and argumentation based models are built and used in a limited number of areas. These areas are often well described, possess reliable data sources (e.g. processing line characteristics) and are single-step oriented (Matser et al., 2010). When dealing with chains of operations, the tools and models become more complex (Bourguet et al., 2013). For complex multiscale systems, we need to further develop sound argumentation and decision support systems integrating a considerable number of variables and interactions; here, one should face the following key elements:

- Surprises: as defined by (Thompson \& Scoones 2009), are the qualitative gaps between perceived reality and expectation in ecological systems. Taking them into account, as well as the so-called technological surprises (Reilly \& Willenbockel 2010) is a major challenge for agri-food systems. These unpredictable events must be considered in management practices besides other social and institutional mechanisms, in order to reduce poverty and increase resilience.

- Uncertainties: many variables are influenced by uncertainties, namely environmental regulations, demand, supply, initial capital cost, technological, biological effects like structure/function relationships, impact of processes and ingredients on quality (Perrot et al., 2011). Interesting reviews and examples related to uncertainties in the biofuel Supply Chain Management can be found for instance in (Doukas, 2013) and (Awudu \& Zhang, 2012). Additionally, if we consider uncertainty in energy sustainability, vague and complex concepts and their implications as a policy objective are difficult to define and measure (Grossman \& Guillén-Gosálbez, 2010). 

2011).

275 Several research questions based on a mathematical programming framework are emerging: how can such a framework manage uncertainty, cope with complex qualitative and quantitative information essential for social and environmental considerations, encompass diverse scales in space

- Complex, qualitative and quantitative information sources, uncertain and incomplete data (Higgins et al., 2010), non-harmonized data acquisition ${ }^{4}$, availability and accessibility of information (Perrot et al.,2011).

- Sustainability metrics: currently available sustainability metrics are mostly devoted to individual organizations, only (Hassini, Surti, Searcy 2012).

- Dynamic adaptive behaviour: a reductionist vision is not enough to understand complex adaptive networks (Surana, Kumara, Greaves \& Raghavan, 2013).

- Heterogeneous problems: market values, environmental, social, legal issues with some indicator measurements difficult to quantify (Meulen, 2013), due to the lack of numerical or probabilistic assessments.

The emerging field of quantitative sociodynamics, an offspring of econophysics, provides some interesting results in dealing with the problems discussed above; using theory and models developed in physics, but reinterpreting them with concepts from the sociology domain (Helbing 2010a, Helbing 2010b).

\subsection{Summary of relevant questions}

In the synthesis of model and real agri-food systems lies a huge research opportunity for mathematical programming, integrative models and decision-support tools (Gupta \& Palsule-Desai, and time, cope with a multivariable dynamic environment, and with scarcity of data. Moreover, how

\footnotetext{
${ }^{4}$ http://www.globalharmonizationinitiative.net
} 
can it deal with different perspectives, types of models, research goals and data produced by conceptually disjoint scientific disciplines, ranging from physics and physiology to sociology and ethics?

These questions are generally addressed separately by laboratories working in fundamental mathematics or computer science, and focus on theoretical, "simple" systems of various disciplines. These approaches should now be integrated and adapted to with regards to sustainability in realworld problems.

A new science corpus should be developed at the frontier of theoretical sciences and agri-food science, where these topics can be addressed. Some directions for building this corpus from the computational perspective are proposed in the next section.

\section{Directions for future research in sustainability}

Some directions are proposed in this section to face the challenge of sustainability in agri-food systems:

- Defining an overarching conceptual scheme: e.g. mathematical resilience,

- Sharing knowledge and expertise: man-machine interactions

- Augmented phenomenology: model construction and decision making.

\subsection{Mathematical resilience perspectives}

When integrating research that spans a number of scales and disciplines, its expedient to introduce an overarching principle or concept. The term "resilience" is often used when the sustainability of a system is analyzed. Resilience is an emergent property of interactions within a system. Quantifying it remains a key scientific challenge (Carpenter et a.I, 2001). The word resilience was first used at the 
end of the nineteenth century in Material Physics to refer to the quality of some metals to resist to stresses and to return to their original shape after a blow. During the 20th century, its use has extended to several other domains, in ecology, economics, social sciences, etc. While the objects change, the underlying idea remains the same: resilience is defined as the capacity of the system under study to keep or restore some properties despite disruptions caused by perturbations (Carpenter et al. 2001). In ecology, the conceptual definition of Pimm (Pimm, 1984), considers resilience as the ability of a system to resist disturbance and the rate at which it returns to its steady state following a disturbance. For Gunderson and Holling (Gunderson \& Holling, 2002), resilience is the capacity of a system to undergo disturbance and maintain its functions and controls and is therefore related to the concept of robustness in control theory (Carlson \& Doyle, 200). As far as operational definitions in the context of ecosystem models are concerned, the main mathematical definitions of resilience are based on dynamical systems theory, and more specifically on attractors and attraction basins (see (Pimm \& Lawton 1977), (van Coller, 1997)). More recently, the viabilitybased measure of resilience (Martin 2004) focuses on the desired properties of the system that do not necessarily correspond to attraction basins, but to an evolutionary development. Moreover, this general definition makes it possible to consider different management actions, and allows the experts to interact with the system and appropriately respond to disturbances (Alvarez, De Aldama, Martin \& Reuillon, 2013). In economics, Martinet and Doyen have been the first to link sustainability with viability concepts. An intergenerational equity feature is naturally integrated within this framework (Martinet \& Doyen, 2007). Moreover, the definition of a set of constraintsbringing together desirable sustainable situations makes it possible to address sustainability as the possibility of finding a path that is an acceptable compromise for all parties (Fuentes, 1993). Since then, (Wei, Alvarez \& Martin, 2013) have shown how the concepts of viability kernels and capture basins allow researchers to take into account spatial and time factors of a sustainability analysis with transient dynamic features. Several sustainability studies using mathematical viability tools have been 
performed, for example in fisheries management (Martinet, Thebaud \& Doyen 2007), (De Lara \&

Martinet 2009), and in forest preservation (Bernard \& Martin 2013).

The main characteristic of the viability theory approach is to emphasize the definition of the ripening process (Sicard et al., 2012)(Mesmoudi et al., 2014).

The viability framework is used to compute the set of possible states and controls from which it is possible to reach a predefined quality target of Camembert cheese (figure 2 presents a result of the computation described in (Mesmoudi et al., 2014)). This procedure makes it possible to evaluate that some ripening times are more crucial for the viable pathways of the state variables than others; at the beginning, for example, few values are admissible; and after 10 days, irreversible phenomena have taken place. This set of possible states contains trajectories that have never been considered by experts so far (Sicard et al., 2012). The exploration of this set makes it possible to find ripening trajectories one-third shorter than the standard procedure, which had never even been contemplated at the beginning of the project, contrary to more traditional criteria such as energy or raw material quantity. In parallel, quality was maintained.

Moreover the knowledge of this set of viable states allows to take into account the distance to the boundary and to define in this way the robustness to perturbation. This approach was validated by experiments at the pilot scale.

When the key variables, constraints (including sustainable ones) and possible controls of an agri-food systems can be identified, the viability approach can establish whether present practices and sustainable objectives are compatible and how. 
Assume we look at a small local Camembert factory that caters a small connoisseurs market of

352 Camembert devotees. Then we can combine two sustainability targets, environmental and cultural;

353 two value systems that have always been intertwined and each of their own form an example of a

354

complex

problem,

and

as

a

combination.

By

355

356

357

358

359

360

361

362

363

364

365

366

367

368

369

370

371

372

373

374

375

including environmental/sustainability parameters/variables/targets to decrease of environmentally

unfriendly output or increasing environmentally positive output, the model built could optimize sustainability targets if combined with optimizing computing tools (cf. chapter 3.3). One of the reasons to use the augmented phenomenology is to effectively optimize the process using the local Camembert expert to safeguard the cultural and uniqueness of the product and the knowledge of environmental experts in the process optimization using the augmented phenomenology as a third party. In this way the process also includes cultural values of the food product that relates the product to the cultural heritage of the region that is essential of its unique taste and structure so recognizable and enjoyed by the connoisseurs (cultural sustainability target) and the environmental sustainability target. Moreover, as culture is not a static phenomenon but a balance result between a conservative cultural dogmas and new innovations, it fits well in the culture development allowing for the evolution of new products out of old ones within the cultural same context; e.g a new variety of Camembert with a distinct taste, structure and smell, a triumph of the "manmachine cooperation". The main limit of the approach is the complexity of the computation which is exponential with the number of state variables. This presently limits practical nonlinear applications to less than 10 variables. Research work is currently performed to overcome this limitation (with the use of classification functions or test methods)

The trade-off between efficiency and resilience remains obvious (Walker et al., 2006, , Carlson \& Doyle, 2000 and ref). Optimizing performance by increasing efficiency in a nonlinear adaptive system is a complex task. Experts have indeed gained the skills to cope with the complexity of their 
environment while keeping the sense of the whole. For example, pilots are able to steer their aircraft in complex environments without losing control. Drawing a parallel with sustainability purposes can be relevant: however, the major bottleneck of these approaches remains the acquisition of knowledge (Hoffman, Shadbolt, Burton, \& Klein, 1995), which is often a difficult and time consuming step (Sicard et al., 2011). Interactive approaches coupling autonomous computations and human expertise thus represent an attractive perspective.

\section{2 Interactions with human knowledge and expertise}

Another question, addressed by several authors, concerns the place of experts and human knowledge in mathematical approaches applied to sustainability. Although several studies analyze expertise both in psychology and artificial intelligence, it is not possible to provide a consensual and operational definition of this notion (Shanteau, 1992). Expertise may include skills, knowledge or abilities in tasks, jobs, games or sports, and is domain-specific (Chi, Feltovich, \& Glaser, 1981). In spite of the diversity of task domains and of expert definitions, literature reports three criteria to define experts: they are better at producing inference, at anticipating dynamics, and have a more functional view of the process (Cellier, Eyrolle, \& Marine, 1997). Finally, experts are characterized by a large number of automatisms and knowledge acquired during practice (Raufaste, Neves, \& Marine, 2003). In human cognition, perceptive processes are an automatic and continuous form of learning (Gibson, 1969). Perception learning is based more on experience (so called SB, for sensory based) than on rules (so called RB, for rules based) (Ballester, Patris, Symoneaux, \& Valentin, 2008), (Valentin, Chollet and Abdi, 2003) show that experts have an advantage in recognition memory: they illustrate that these higher performances are likely derived from more efficient coding and retrieval of longterm memories. One of the efficient coding mechanisms used by experts is the cognitive "chunk" recognition (Chase \& Simon, 1973). A "chunk" is a grouped set of variables, taken from a situation, 
that are closely related to each other. These variables are acquired through experts' sensorial

402

403

404

405

406

407

408

409

410

411

412

413

414

415

416

417

418

419

420

421

422

423 perceptions.

Operational research is a discipline that deals with the application of advanced analytical methods to help make better decisions. This is an active field in the domain of sustainability, where expertise has an important role. Higgins et al. (Higgins et $a l .2010$ ) have underlined the following key elements:

- Mathematical representation of the problems (integer or linear programming) is not generally consistent with the way in which the decision maker understands the problem when constructing the solution. Approaches should take into account this dimension and integrate it iteratively, for instance through an interface with the decision makers (figure 3, from Miller et al., 2010), where authors propose a structure where a participatory process is embedded iteratively in the loop of an algorithm. Integration is performed at the validation level.

[Figure 3 about here]

- Quantifying factors considered by experts when generating a desired solution is hard; often solutions are found through extensive exploration, and not focusing on efficiency and inclusion of feedback loops.

- Data requirements and uncertainties may be huge.

- Whole-of-chain system understanding of practical problems, particularly when social and environmental drivers are concerned, is difficult to reach for the industry and practitioners.

Another element is given by (Melnik, 2009): with the increasing complexity of technological systems that operate in dynamically changing environments, the relative share of human errors is increasing across all applications. This means that human errors can no longer be ignored (or eliminated easily 
by conventional formal statistical methodologies) but should be integrated into the modeling framework.

426

427

Reilly and Willenbockel (2010) propose to consider uncertainty, complexity and diversity as means to enhance adaptability of agri-food systems; by contrast, current policies and practices aspire to maintain the status quo or to control change in systems assumed to be stable. In other words, this implies a radical change from reactive to proactive system approaches. Improving the process of innovation via knowledge sharing is strongly linked to the ability of models to capture not only the planned but also the unplanned outputs of knowledge sharing (Miles \& Snow, 2007; Zwart et al, 2006). Computer aided design must help the person or group to communicate easily and generate more and richer ideas (encourage generation of diverse even inept ideas that carry potential for new ideas), while maintaining their diversity.

Applied to manufacturing processes, where generally the assessment of alternative solutions is based on life cycle assessment, (LCA), some contributions have been developed the frontier of artificial intelligence, to take into account expert knowledge. Authors like (Giovannini et al., 2012) used for example ontologies that implement a support to sustainable manufacturing. The authors' main statement is that a cultural shift is required that involves in-depth software and hardware insights in manufacturing processes. They propose to design a KBS (knowledge based system) simulating the role of a sustainable manufacturing expert, who is able to automatically identify change opportunities and to propose alternatives. The human dimension is thus included and considered in the cost function evaluation. The next step is to integrate not only the external evaluator role within a more or less balanced system but in a full network that link local connections and from which global properties emerge.

For instance, a tool that is currently available to explore multi-dimensional data sets is EvoGraphDice. It is based on the EVE framework (Evolutionary Visual Exploration) (Boukhelifa et al., 2013). This 
448

449

450

451

452

453

454

455

456

457

458

459

460

461

462

463

464

465

466

467

approach for data exploration combines a classic interactive visualization technique (a scatterplot matrix with linked views) with evolutionary stochastic optimization. The EvoGraphDice prototype extends the concept of principal component analysis of scatter plots by using interactive optimization to evolve a population of secondary axes of observations as linear or nonlinear combinations, thus providing users with nontrivial views on their data.

However, current projection axes are not defined from the mathematical structure of the model in hand; rather they are dynamically generated to favor views showing an interesting visual pattern to the user where the notion of "interesting" is defined dynamically using an image-based metric and subjective user ranking of views.

The EVE framework could be further extended to take into account different types of knowledge, both quantitative and qualitative (e.g. mathematical structures, statistical information, or confidence level), to better guide the exploration to pertinent areas of the search space. The uncertainty itself could be fed into the interactive evolutionary algorithm such that user exploration is driven towards more certain (or informative) areas of the search space. Whereas Scatterplot Matrices (SPLOMs) are effective for visualizing small to medium-sized static multidimensional data sets, new scalable visualization techniques need to be investigated to better visualize time-varying scale-dependent relationships between a large number of dimensions (e.g. using dynamic networks instead of or linked to the SPLOM). In this new context, new navigation techniques are also required to allow for the smooth transitioning between the different scales and types of data (e.g. using appropriate animated transitions). 


\subsection{Optimization}

470

471 Optimization in the context of complex adaptive systems is far more difficult than when dealing with

472 plain systems based on sequences of static configurations; the latter has been extensively 473 elaborated, for example in chemical engineering (Grossmann \& Guillén-Gosálbez, 2010; Lainez \& 474 Puigjaner, 2012).

475 Optimization is used for various purposes: in this work, we are mainly interested in (a) building 476 models, learning their parameters and structures from available data and knowledge; and (b) using 477 such models in decision-making processes.

478

479

480

481

Optimizing the efficiency and resilience of an entire industry, as a network of business partners and competitors, is fundamentally different from optimizing each individual business unit within the context of that industry (Miller et al., 2010). However, contemporary management is based almost entirely on the optimization of individual business units for static "average" conditions. Influences arising from states and dynamics above and below the scale of interest are ignored, but affect the ability of the system to reorganize and resist after some disturbance (Walker et al,2006). Furthermore it should be noticed that integer or linear program optimization strategies can have a small spatial or temporal range in terms of predicting the effects of an action if the system exhibit strong nonlinear properties. Depending on the point in parameter space, the variable underlying distributions or phase space can change, leading to different dynamics and equilibriums or steady state solutions. Moreover, these systems evolve; intervention, control mechanism and innovations introduce new objects and relations, affecting the fitness landscape of the function to be sustained or other seemingly unrelated important processes. Therefore optimization should be viewed as a continuing dynamic and adaptive process. 
As said above, the implication of single human users or groups of users in optimization processes is a

493 challenging question (for dealing with expertise on model building, decision making, control, 494 monitoring, data gathering, tacit knowledge, etc.). Techniques involving human expertise in optimization processes are sometimes referred to as humanized optimization (Takagi, 2008).

Even more difficult but strategic issues are related to optimization for decision making in a

While potentially very effective, humanized optimization has several important limitations, the major one being user fatigue, the tendency of human users to lower the quality of their assessment as the time spent interacting with an algorithm increases. There is a considerable amount of literature on compensating or limiting user fatigue (Lam, 2008): concerning model building, a possible approach is to let the user itself set the pace of the procedure. (Tonda et al., 2014), for instance, proposes a framework for Bayesian network structure learning, capable of producing probabilistic graphical models with a semi-supervised approach. The framework is tested by two experts in food science, using datasets from food processing, and while the results are satisfying, further limitations are uncovered: given the choice between multiple learning algorithms, users show a predominant preference for quick and sub-optimal algorithms, with respect to slower, more effective ones. Thus, it seems that the expert would rather see the immediate result of his/her ideas, more than obtain the best possible approximation. Another limit of this approach concerns the number of variables that a human can manage: even when interacting with a graphical model, users cannot successfully analyze more than a few tens of nodes. This limit is also true for the advanced visualization methods discussed in paragraph 3.2. These are non-trivial insights that should be taken into account for devising further methods combining human expertise and machine learning. 
In order to design efficient optimization algorithms, various points need to be addressed: structure of the search space (for instance with mixed variables), constraints, and optimisation aims (mono- or multi-criteria objectives) (Pavone and Coello Coello, 2012). The question of multiple conflicting aims can be tackled using multi-objective optimization tools (Miettinen and Sayin, 2013), providing the user with a full range of optimal compromises, called Pareto front. Even if the Pareto front might be large and hard to understand for a human user, efficient decision tools and ad-hoc visualization techniques can help the user to efficiently explore the set of proposed solutions, and finally take a decision (Coello Coello, 2009).

\section{Examples}

\subsection{Multi-scale analysis in the chemical industry}

Sustainability is indeed largely addressed by the chemical industry, in particular in process synthesis. A review about this topic can be found in (Nicopoulou and Lerapetritou, 2012). Several scales can be considered as depicted by (Lainez \& Puigjaner, 2012). An example among others is related to a biofuel chemical plant (You, Tao and Snyder, 2011), where several configurations at the equilibrium are tested. The focus of this work is not only on the manufacturing process but also on the supply chain. Numerical approaches like MILP (multiperiod, mixed integer linear programming) and MOO (multiobjective optimization) are widely used to reduce costs in process synthesis by choosing the best organisation at the equilibrium. The strategy is based on the following steps (Grossmann \& Guillén-Gosálbez, 2010): (1) development of a representation of alternatives, (2) formulation of a mathematical program for the selection of the configuration and operating levels that involve discrete and continuous variables, (3) the solution of the optimization from which the optimal solution is selected. Several optimization methods have been tested in literature, from gradient search to global ones, as tabu-search or evolutionary algorithms. 
The drawback of system dynamics models (type MILP) is that the structure has to be defined before

541 the simulation starts. Another drawback of these chemical engineering applications is that

542 optimization is achieved on solutions at the equilibrium of the system, and transient dynamics are

543 disregarded. Queuing theory has primarily been used to address the steady-state operation of a

544 typical network. Mathematical programming has also been used to solve the problem of resource

545 allocation in networks. This is meaningful when dynamic transients can be disregarded, which is not

546 always relevant with regards to the problem tackled. A useful paradigm for modelling a supply chain,

547 taking into consideration the detailed patterns of interaction, is to view the process as a network

548 involving interacting agents: (Surana, Kurava, Greanes \& Raghavan, 2013) propose an approach

549 originating from complexity theory: an agent-based model, or 'bottom-up approach', simulates the

550 underlying processes that yields a global pattern. This makes it possible to evaluate which

551 mechanisms are the most influential in producing the emergent pattern. Networks are inherently

552 difficult to understand due to their structural complexity, evolving structure, connection diversity,

553 dynamical complexity of nodes, node diversity and meta-complication where all these factors

554 influence each other.

555 If we translate this to agri-food systems, it becomes even more crucial to consider many agents and

556 scales, and especially their reciprocal interconnections. Embodying scales in this domain means also

557 taking simultaneously into account structure, function, preferences, acceptance, perception and

558 needs. If this viewpoint is shared with the chemical industry (Charpentier, 2010) (see figure 4) there

559 is an increased complexity due to the nature of living phenomena and their environmental impact on

560 the entire system. As a consequence, sustainability approaches include the molecular level (even

561 down to sub-atomic levels), i.e. the scale guiding the dynamics of structure-function relationships

562 and biological processes around equilibrium, up to the factory level and beyond. Territory mega scale

563 level may even be considered when sustainability purposes are investigated. In this context, 
sustainable solutions emerge from transient states and not only at equilibrium. This makes it possible to include human interventions, both locally and globally.

[Figure 4 about here]

\subsection{Multi-scale analysis in biological processes}

An interesting example of multiscale challenge is the management of the ecosystems in agri-food systems. Microbial ecosystems are present everywhere (e.g. in soil, animal gut, food products and marine sediments). Understanding their multi-scale properties to be able to make predictions is of major importance to life sciences (Faust and Raes, 2012). The assessment of microbial ecosystems mechanisms, from gene expression to emergence of functional properties is a challenging issue for several reasons, including the presence of many scales, uncertainties, out of equilibrium (instability), and complex quantitative (generally big data) and qualitative information (a long scientific descriptive expertise).

Ecosystems are involved in a large variety of food systems. For example one typical microbial ecosystem widely studied is cheese. Cheese is one of the oldest dairy products and, nowadays, constitutes the most diverse group of dairy products with several hundreds of distinct varieties. It involves a dairy industry that plays a key role in the French economy with 27.7 billion income and 3.6 billions trade surplus in 2013, representing over 250000 jobs.

Cheese ripening is a complex process involving a range of microbiological and biochemical reactions. During this process, three major biochemical events occur: lactose consumption, lipolysis, and proteolysis. These catabolic reactions are responsible for the production of various compounds including volatile aroma compounds which play an important role in flavor perception.

The cheese microflora is characterized by a high cell density, as it can reach more than one billion cells per gram of cheese. It is composed of both aerobic members, i.e. those developing on the 
588

589

590

591

592

593

594

595

596

597

598

599

600

601

602

603

604

605

606

607

608

609

610

611

612

cheese surface such as microorganisms found in the rind of soft cheeses, and anaerobic, i.e. those growing inside the curd like species found in the middle of hard cheeses. The main technological activities sustained by the microbial community regard the matrix biodegradation which lead to the development of interesting organoleptic properties (cheese sensory quality), and the potential protection effect against spoilage microorganisms and pathogens (cheese safety).

A large microbial diversity has already been isolated from cheese products, providing an important resource of cultivable microbes for microbiological, biochemical and molecular analyses. It mainly contains Firmicutes (lactic acid bacteria, staphylococci), Actinobacteria (coryneform bacteria), Proteobacteria, Bacteroidetes, yeasts and moulds. Recent inventories of the cheese microbial diversity allowed estimating that almost three hundred different species might inhabit cheese products. For example, microbial interactions between ripening microorganisms have been highlighted by co-culturing isolated strains in experimental cheeses providing key knowledge on competitions or growth inhibitions occurring in cheese (Mounier et al., 2008) but not completely explained. In parallel, meta-omics analyses were conducted on a reduced ecosystem composed of nine microorganisms in which keystone species omissions were experimented. This project generated $>300 \mathrm{~GB}$ of meta-transcriptomic data corresponding to the expression level of 37,923 individual genes as well as numerous associated physico-chemical, biochemical and metabolomic data. The classification of the expression data from those genes into functional classes made possible to obtain an overview of the metabolic activities of the nine microorganisms composing the ecosystem (Figure 5). Nevertheless from those study to the mathematical prediction and simulation of the system, there is a gap not yet filled in.

In such a complexity (limited in comparison to the intestinal microbiota!), there is still a gap that needs to be bridged between the molecular scale information (genetic, expression, compounds detection) and the macroscopic properties (e.g. flavor for a cheese) (Landaud, Helinck \& Bonnarme, 2008). Several reasons can explain this fact. 
First, the chemical compounds, particularly the products that are secondary metabolites for well-

614 known metabolic functions are often not connected to metabolic models due to the lack of genetic information. Emergence of macroscopic properties from genome expression using classical bioinformatics tools is then still limited. If knowledge can be found in several descriptive studies about microbial communities, it is not often exploited because it generally needs a huge work of extraction and formalization (Liu et al., 2014).

A second reason is related to the scale of observation of the mechanisms involved. Indeed, if several works are achieved regarding a single organism based on genome-scale metabolic network (see Bordbar et al., 2012 and Wodke et al., 2015 for examples), few have proposed to manage an in situ metabolic activity of a microbial community (Bowen et al., 2014). Generally the focus of such studies is on the description, sometimes the modelling of the metabolic detailed pathways and their associated chemical compounds.

It is not at all easy to manage a balance between (1) a detailed description of each compound of the metabolism pathways for one microorganism and (2) an ability to cut across the individual scale to go through an in situ expression of a community. Computing problems arise as well as an uncertainty on the scales needed to extract a synthetic architecture able to predict the emergence of macroscopic functionalities. Moreover, reconstructing multiscale dynamics of the in situ community, involves finding a mathematical structure able to organize in a relevant way the links between the scales and variables. Nevertheless, the optimal way to structure and aggregate the knowledge embedded in the big database available and in the heuristics manipulated by experts is not an easy task to achieve. This is why we have to work on how to develop optimal mathematical structures (cf. chapter 3.3); and macro-structures) should be bridged. Even more, the bridge needs to be extended towards the 
637

638

639

640

641

642

643

644

645

646

647

648

649

650

651

652

653

654

655

656

657

658

659

660

661

662

flavour and structure perceptions of consumers. Even though those perceptions are individual - and highly dependent on the environmental conditions during consumptions, cultural values, etc - one needs to (1) abstract collective information in order to efficiently adapt products offers with demands and (2) understand the underlying consumer preferences. Concerning the latter, quantitative sociodynamics could help in better understanding those preferences. The first requires handling of complex data sources and optimization processes in order to let emerge collective properties.

\subsection{Sustainability of networks by collective regional branding.}

France is characterized by strong regional forces and relevant connected activities. Their "pôles de compétitivité" ("competitive clusters") are recognized by the European Commission as a source of innovation and employment, while maintaining and enforcing traditional values (EC report on regional policy for sustainable growth, see below). Linked to local cultural values, these clusters show a diversity of multi-scale characteristics, dynamical patterns (Porter, 2000), resilience, (intuitive and strategic) decision making and optimization steps, either by a 'hierarchic leader' or by the stakeholders within the cluster. Two key examples are the collective regional food marketing initiatives "Produit en Bretagne" (North-West of France; region Brittany) and "Sud de France" (South of France, region Languedoc-Roussillon).

The first is a private, entrepreneurial-driven network of food companies that have developed a common regional brand for typical products. It has slowly evolved into a strong business network of nearly 300 companies in Bretagne, sharing not only a common commercial ambition, but also cultural values and ethical principles as solidarity and sustainability. It is a key example of a selforganized complex system in which the stakeholders and their interactions - either intuitively or via joint strategic actions - result in resilience accompanied by periodically renewed emerging properties 
663

664

665

666

667

668

669

670

671

672

673

674

675

676

677

678

679

680

681

682

683

684

685

686

687

688

showing the diverse quality characteristics of their products. "Produit en Bretagne" is one of the oldest European regional brands.

The second example, "Sud de France", is a public policy-driven initiative to promote products of the Languedoc-Roussillon; the major reason to create the brand in 2006 was the decline in sales of regional wines, due to an increasing worldwide competition and low appreciation of their origin. As the largest region of wine production worldwide, this tendency should be counteracted according to policy makers. Step by step, wine producers have been persuaded to use the "Sud de France" label; later on, the brand has been extended to other food producers and to sustainable tourism. The brand is even used as institutional tool, labeling other sectors, as logistics, sport, culture, research etc., raising its complexity. Wine export has been rising afterwards, and over 3000 companies have joined the initiative, which currently brings 9.400 different agricultural products and 850 quality tourism services under the banner "Sud de France". However, it is not adopted by the companies in a sense that they have fully taken over the investment and running costs of this joint marketing action; it is still a publicly funded marketing offensive (Donner et al., 2014). Thus, one could conclude that involved stakeholders of "Sud de France" are not yet fully embedded in a regional cluster (Uzzi, 1996), neither the brand has evolved in a dynamic, self-organised, network.

Here, the full complexity of the regional food system is recognized, as well as its players (agents) and their interactions, the diversity of products - and their overall quality and functional properties and production chains (including local and global resources), its (historical) development, emerging properties and new perspectives at local and global scale for a wide range of consumers. Boundary conditions also impact the system as a whole, including regional branding restricted usage, protection of origin labels, global trade regulations, protective measures, global price volatility, political changes, public and/or private investments, etc. A key feature is the leading role of the Region Languedoc Roussillon, with periodically large investments and extensive marketing initiatives trying to optimize the overall output of the Sud-de-France region. Hence, the various regional 
689

690

691

692

693

694

695

696

697

698

699

700

701

702

703

704

705

706

707

708

709

710

711

712

activities show a multitude of patterns, from periodical but rather static, up to highly chaotic. The activities in between seem to balance well at the edge of order and chaos, and would most likely reveal resilience and a high level of self-organization, in this case supervised by the Region LR who is major decision maker, at all scales from molecular level (recognized functional properties of their products) up to global scales (recognized marketing related to a well-appreciated country of origin cluster).

As stated by the Santa Fé institute (Kaufmann, 1995) (self-organization in complex systems) and by Helmsing and Vellema (Helmsing \& Vellema, 2011) (socio-technological innovations and embedding), the design of a full technological-socio-economical food system deserves to be a major research line. A multi-disciplinary approach for qualitatively and quantitatively analyzing complex regional branding for high quality and diverse products, combining several disciplines such as economics, mathematics, marketing, politics, sociology or geography (Dinnie, 2004), together with engineering, agri-food and bio-based sciences, is needed in order to better understand the success and failures of regional clusters.

Practically, we propose the following strategy to achieve those new insights and to give sound recommendations. Step 1 concerns painting a picture in time (including thus its history) of a territory marketed via a common brand, including products and their distinct values locally and globally, stakeholders involved and their interactions, regional characteristics, boundary conditions and incentives, ... Step 2 considers the different scales all along the chain from resources and product quality characteristics towards final characteristics appreciated by target groups of consumers. Step 3 addresses a first complex system model in which the rigidity, resilience and chaos situations of the territorial cluster(s) are incorporated. Step 4 analyzes in more detail the emergent properties of the cluster in which new products are (co-)developed, marketed, ... Step 5 focuses on which optimization steps are carried out and by whom as decision makers in order to better position a competitive 
cluster. Step 6 includes a repetitive procedure to further optimize the complex system approach to better adapt the complex system to the realistic conditions.

\section{Conclusions}

To conclude, even if some approaches -- agent-based approaches among the most representative ones -- are already available and applied to some fields of research like embryogenesis (Olivier et al., 2010) and urban simulations (Irwin, 2010), there is a clear need for efficient, intensive and parallel computational methods for the agri-food domain (Reuillon, Traore, Passerat-Palmbach and Hill, 2012).

At present, several issues remain unanswered:

- Find the right level(s) of description to simulate the system. The answer will generally be strongly connected to the objective of the study and at present a methodology to find the right level(s) does not exist and should be rediscovered for each application without any guarantee of relevance.

- Multiscale reconstruction limitations: progress has been done on computational tools to manage uncertainty, for example Bayesian formalisms, theory of possibility on heuristics manipulated by humans, stochastic approaches applied to different mathematical representation ie on individual based models, ontology-based data access. Nevertheless, used independently these solutions require lots of knowledge or data at each scale while only some of them are available (cf. example chapter 4.2). Moreover, even with a big data basis, without any oriented structured approach, a part of the knowledge is lost or unusable. In this sense there is a necessity to propose tools for coupling heterogeneous model and knowledge and connect different computing communities (see the smart data tendency).

- Parameters tuning limitations: another limitation is linked to the necessity for those approaches to tune empirically some parameters: graph and discretization for the DBN; 
indexation for the data mining; parameters of the stochastic laws, far more complex to be tuned than parameters of known physical laws; parameters of the optimization algorithms or other Al algorithms. Some new research focusses on this point at present (interactive learning, visualization).

- Computational limitations: if stochastic approaches are really well adapted to the multiscale reconstruction in an uncertain context, it relies on a high capacity of computation. Even if now the computational power is largely increased, with clusters of computers, the number of variables that could be manipulated by some approaches is still limited: for example, less than 10 for the viability theory (cf. chapter 3.1), 5 variables for the approaches of optimization coupled to visualization (cf. chapter 3.3),....

- Visualization and user fatigue limits: all methods based on machine-man interaction impose a consistent exertion on the expert (Lem, 2008), often referred to as user fatigue. While semi-supervised learning of models through graphical user interfaces can be very effective, combining the best aspects of machine learning and expert knowledge, the strain imposed on the user severely limits the effectiveness of these approaches.

Decision making in sustainability management of agri-food systems will require building a science able to cope with uncertainty, emergence of properties, multi-scale reconstruction, optimization of non-linear systems in dynamic environments, interactive learning and human expert knowledge, non-equilibrium exploration and dynamical behavior at the edge between order and chaos. Building models is essential, but highly difficult and allows for plenty opportunities for the mathematical and computational sciences; it will need a strong iterative interaction combining computational intensive methods, formal reasoning and the experts of the different fields.

Although generic methods are still not available and relevant expert knowledge dispersed, complex 
762

763

764

765

766

767

768

769

770

771

772

773

774

775

776

777

778

779

780

781

782

783

784

especially in-depth research at interfaces of previously considered separated scales, as illustrated here. The key building blocks of efficient methods have been addressed, as well as the way they potentially could contribute to a generic complex system approach. Table 1 is a synthesis of the steps required for an approach of the complex problem of sustainability of food systems, the work realized in this direction, reachable or more difficult to achieve, and a list of mathematical or computing tools already available or under study at present. As a next step, we need to enter a technological-socioeconomical regime in which scales are interlinked in order to develop a flexible but rigorous concept for the complex system approach. Then, this would make it possible to come up with practical tools for decision makers who are facing challenges on sustainability.

[Table 1 about here]

\section{Perspectives}

We need to come up with more radical innovations and solutions integrating all (linked) scales, with the help of a generic approach as proposed here, in order to maintain a viable planet; if not, our current innovations may only extend the "expiration date" of our planet. We are convinced that a creative, multi-scale, multi-discipline and complex system approach is able to provide tools that are needed to tackle the current challenges in research, development and business strategies.

Our society is facing challenges that have to be approached with new strategies. The review of current trends for the obesity, growth of world population, atmospheric levels of greenhouse gases, national debt of countries, all exhibit a common feature, that is a (near) exponential growth. This growth is incompatible with balanced systems. These systems show periodic changes but always 
return to an attractor or a stable position after a given period. The optimization of such out-of-theequilibrium systems should rely on the stochasticity of the signal during a significant time. Innovations relying on integrated and deep knowledge, may help in trying to level off exponential curves.

\section{Acknowledgements}

The authors would like to thank all participants of the duALIne project, and in particular $\operatorname{Dr} C$. Esnouf for her help; Acknowledgement for the financial support of government (French ANR project INCALIN). Acknowledgment for the funding received from the European Community's Seventh Framework Program (FP7/2009-2013) under grant agreement DREAM No. 222654-2.

\section{References}

Alvarez, I., de Aldama, R., Martin, S., Reuillon, R., Aug. 2013. Assessing the resilience of bilingual societies: coupling viability and active learning with $\mathrm{kd}$-tree. application to bilingual societies. In: IJCAI $2013 \mathrm{AI}$ and Computational Sustainability Track. Beijing, China, pp. 2776-2782.

Alvarez, I., de Aldama, R., Martin, S., Reuillon, R., 2013. Assessing the resilience of socio-ecosystems: Coupling viability theory and active learning with kd-trees. In: IJCAI 2013, Proc. of the 23rd International Joint Conference on Artificial Intelligence pp. 2776-2782.

Aubin, J., 1991. Viability Theory. Birkhauser, Basel.

Awudu, I., Zhang, J., 2012. Uncertainties and sustainability concepts in biofuel supply chain management: A review. Renewable and Sustainable Energy Reviews 16, 1359-1368.

Baudrit C., Wuillemin, P.H., Perrot, N. (2013). Parameter elicitation in probabilistic graphical models for modelling multi-scale food complex systems" Journal of food engineering, 115(1), 1-10.

Bernard, C., Martin, S., 2013. Comparing the sustainability of di_erent action policy possibilities: Application to the issue of both household survival and forest preservation in the corridor of fianarantsoa. Mathematical Biosciences 245 (2), 322-330.

Bordbar, A., Mo, M.L., Nakayasu, E.S., Schrimpe-Rutledge, A.C., Kim, Y.M., Metz, T.O., et al. Model-driven multiomic data analysis elucidates metabolic immunomodulators of macrophage activation. Mol Syst Biol. 2012;8. doi:10.1038/msb.2012.21

Boukhelifa, N., Cancino, W., Bezerianos, A. and Lutton, E., 2013. Evolutionary Visual Exploration: Evaluation With Expert Users. Computer Graphics Forum (EuroVis 2013, June 17--21, 2013, Leipzig, Germany), Eurographics Association, 32 (3). 
Bowen, J.L., Babbin, A.R., Kearns, P.J., Ward, B.B., 2014. Connecting the dots: linking nitrogen cycle gene expression to nitrogen fluxes in marine sediment mesocosms. Aquat Microbiol, 5, 429. doi:10.3389/fmicb.2014.00429.

820

821

822

823

824

825

826

827

828

829

830

831

832

833

834

835

836

837

838

839

840

841

842

843

844

845

846

847

848

849

850

851

852

Bourguet, J.R., Thomopoulos, R., Mugnier, M.L., Abecassis, J. 2013. An Artificial Intelligence-Based Approach to Deal with Argumentation Applied to Food Quality in a Public Health Policy. Expert Systems with Applications, 40 (11): 4539-4546.

Bousson, K., Steyer, J.P., Travé-Massuyès, L. Monitoring and diagnosis of fermentation processes, in Issues of Fault Diagnosis for Dynamic Systems, (Ed. Patton, Franck and Clark), Springer-Verlag, 2000, ISBN 3-540-199683.

Carlson, J., \& Doyle, J. (2000). Highly Optimized Tolerance: Robustness and Design in Complex Systems. Physical Review Letters, 84(11), 2529-2532.

Carpenter, S., Walker, B., Anderies, J., Abel, N., 2001. From metaphor to measurement: resilience of what to what? Ecosystems 4, 765-781.

Charpentier, J., 2010. Among the trends for a modern chemical engineering, the third paradigm: The time and length multiscale approach as an e_cient tool for process intensification and product design and engineering. chemical engineering research and design $88,248-254$.

Coello Coello, C. A., 2009. Evolutionary multi-objective optimization: some current research trends and topics that remain to be explored. Frontiers of Computer Science in China 3 (1), 18-30. URL http://dx.doi.org/10.1007/s11704-009-0005-7

De Lara, M., Martinet, V., 2009. Multi-criteria dynamic decision under uncertainty: A stochastic viability analysis and an application to sustainable fishery management. Math. Biosci. 217 (2), 118-124.

Dinnie, K., 2004. Place branding: overview of an emerging literature. Place Branding, 1, 106-110.

Donner, M., Fort, F., Vellema S., 2014. How to capture place brand equity? The case of Sud de France. Place branding and public diplomacy (forthcoming).

Doukas, H., 2013. Modelling of linguistic variables in multicriteria energy policy support. European Journal of Operational Research 227 (2), 227-238.

Dovers, S. R., Handmer, J. W., 9 1993. Contradictions in sustainability. Environmental Conservation 20, 217222. URL http://journals.cambridge.org/articleS 0376892900022992

Dugat-Bony, E., Straub, C., Teissandier, A., Onésime, D., Loux, V., Monnet, C. et al. (In Press). Overview of a surface-ripened cheese community functioning by meta-omics analyses. PLOS ONE. In press.

EC Document, 2011 Regional Policy contributing to sustainable growth in Europe ; ISBN: 978-92-79-20333-6; doi:10.2776/39448 published by European Commission, Directorate-General for Regional Policy

Edwards, M., 2006. Product engineering: some challenges for chemical engineering. Chemical Engineering. Research and Design, TransICheme 84, 255-260.

Faust, K., Raes, J., 2012. Microbial interactions: from networks to models. Nat Rev Microbiol. 10, 538-550. doi:10.1038/nrmicro2832 
Fengqi You, F., Tao, L., Graziano, D., Snyder, S., 2012. Optimal design of sustainable cellulosic biofuel supply chains: Multiobjective optimization coupled with life cycle assessment and inputoutput analysis. AIChE Journal 58(4), 1157-1180.

Fuentes, R. E., 1993. Scientific research and sustainable development. Ecol. Appl. 3, 576-577.

Giovannini, A., Aubry, A., Panetto, A., Dassisti, M., Haouzi, H., 2012. Ontology-based system for supporting manufacturing sustainability. Annual Reviews in Control 36, 309317.

Grossmanna, I., Guilln-Goslbez, G., 2010. Scope for the application of mathematical programming techniques in the synthesis and planning of sustainable processes. Computers and Chemical Engineering 34, 13651376.

Gunderson, L., Holling, C. S., 2002. Panarchy : understanding transformations in human and natural systems. Island Press, Washington, D.C., USA.

Gupta, S., Palsule-Desai, O., 2011. Sustainable supply chain management: Review and research opportunities. IIMB Management Review 23, 234-245.

Hassini, E., Surti, C., Searcy, C., 2012. A literature review and a case study of sustainable supply chains with a focus on metrics. Int. J. Production Economics 140, 69-82.

Helbing, D., 2010a Pluralistic Modeling of Complex Systems CCSS-10-009, http://ssrn.com/abstract=1646314.

Helbing, D., 2010b. Quantitative Sociodynamics, Springer Berlin Heidelberg.

Helmsing, A.H.J., Vellema, S., 2011. Value Chains Governance and Inclusive Endogenous Development: Towards a Knowledge Agenda. Development policy review network (DPRN), 2011.

Higgins, A., Miller, C. J., Archer, A., Ton, T., Fletcher, C., McAllister, R., 2010. Challenges of operations research practice in agricultural value chains. Journal of the Operational Research Society 61, 964 -973.

Holling, C., 1973. Resilience and stability of ecological systems. Annual Review of Ecology and Systematics 4, 124.

Holling, C. S., 2001. Understanding the complexity of economic, ecological, and social systems. Ecosystems 4, 390-405.

Kauffman, S., 1995. At Home in the Universe, The Search for the Laws of Self-Organization and Complexity. Oxford University Press.

Lainez, J., Puigjaner, L., 2012. Prospective and perspective review in integrated supply chain modeling for the chemical process industry. Current Opinion in Chemical Engineering 1, 430-445.

Lam, Heidi, 2008. A framework of interaction costs in information visualization. Visualization and Computer Graphics, IEEE Transactions on 14.6, 1149-1156.

Landaud, S., Helinck, S., Bonnarme, P., 2008. Applied Microbiology and Biotechnology 77, 1191 (Jan, 2008).

Lehmann, R., Reiche, R., Schiefer, G., 2012. Future internet and the agri-food sector: State-of-the-art in literature and research. Computers and Electronics in Agriculture 89, 158-174. 
Liu, M., Bienfait, B., Sacher, O., Gasteiger, J., Siezen, R.J., Nauta, A., et al., (2014). Combining Chemoinformatics with Bioinformatics: In Silico Prediction of Bacterial Flavor-Forming Pathways by a Chemical Systems Biology Approach “Reverse Pathway Engineering." PLoS ONE, 9: e84769. doi:10.1371/journal.pone.0084769

Martin, S., 2004. The cost of restoration as a way of defining resilience: a viability approach applied to a model of lake eutrophication. Ecology and Society 9 (2). URL http://www.ecologyandsociety.org/vol9/iss2/art8.

Martin, S., Deffuant, G., Calabrese, J., Gilbert, N., 2011. Defining resilience mathematically: from attractors to viability. Understanding complex systems. Springer. URL http://cemadoc.cemagref.fr/cemoa/PUB00033173.

Martinet, V., Doyen, L., 2007. Sustainability of an economy with an exhaustible resource: A viable control approach. Resour. Energy Econ. 29 (1), 17-39.

Martinet, V., Thebaut, O., Doyen, L., 2007. Defining viable recovery paths toward sustainable fisheries. Ecol. Econ. 62 (2), 411-422.

Matser, A., Quataert M., Hamoen R., de Vries HSM, 2010. Decision Support System. New Food, Issue 5, P. 65 69

Melnik, R., 2009. Coupling control and human factors in mathematical models of complex systems. Engineering Applications of Artificial Intelligence 22, 351-362.

Meulen, B., 2013. The structure of european food law. Laws 2, 69-98. 2.

Mesmoudi, S., Perrot, N., Reuillon, R., Bourgine, P., Lutton, E., 2010. Optimal viable path search for a cheese ripening process using a multi-objective ea. (2010). ICEC 2010. International conference on evolutionary computation. 24-26 October Valencia (Spain).

Mesmoudi, S., Alvarez, I., Martin, S., Reuillon, R., Sicard, M., Perrot, N., 2014. Coupling geometric analysis and viability theory for system exploration: Application to a living food system. Journal of Process Control, 24, 1828.

Miettinen, K., Sayin, S., 2013. Special issue: 21st international conference on multiple criteria decision making; articles on multiobjective optimization. Journal of Global Optimization 57 (2), 279-280. URL http://dx.doi.org/10.1007/s10898-013-0041-6.

Miles, R., Snow, C., 2007. Organization theory and supply chain management: An evolving research perspective. Journal of Operations Management 25, 459-463.

Miller, K., Charles, A., Barange, M., Brander, K., Gallucci, V., Gasalla, M., Khan, A., Munro, G., Murtugudde, R., Ommerj, R., Perry, R., 2010. Climate change, uncertainty, and resilient fisheries: Institutional responses through integrative science. Progress in Oceanography 87, 338-346.

Mounier, J., Monnet, C., Vallaeys, T., Arditi, R., Sarthou, A-S., Helias, A. et al. (2008). Microbial Interactions within a Cheese Microbial Community. Appl Environ Microbiol. 74: 172-181. doi:10.1128/AEM.01338-07.

Mouzé-Amady, M., Raufaste, E., Prade, H., \& Meyer, J.P. (2013). Fuzzy-TLX: using fuzzy integrals for evaluating human mental workload with NASA-Task Load indeX in laboratory and field studies. Ergonomics, 56 (5), $752-$ 763.

Neubert, M., Caswell, H., 1997. Alternatives to resilience for measuring the responses of ecological systems to perturbations. Ecology 78 (3), 653-665. 
Nikolopoulou, A., lerapetritou, M., 2012. Optimal design of sustainable chemical processes and supply. chains: A review. Computers and Chemical Engineering 44, 94-103.

Olivier, N., Luengo-Oroz, M., Duloquin, L., Faure, E., Savy, T., Veilleux, I., e. a., 2010. Cell lineage reconstruction of early zebrafish embryos using label-free nonlinear microscopy. Science 329, 967- 971.

Pavone, M., Coello Coello, C. A., 2012. Optimization on complex systems. Memetic Computing, 1-2.

Perrot, N. (2006). Fuzzy concepts applied to food product quality control. Editorial. Fuzzy Sets and Systems, $157,1143-1144$.

Perrot, N., Trelea, I. C., Baudrit, C., Trystram, G., Bourgine, P., 2011. Modelling and analysis of complex food systems: State of the art and new trends. Trends in Food Science \& Technology 22 (6), 304-314.

Pimm, S., 1984. The complexity and stability of ecosystems. Nature 327, 321-326.

Pimm, S., Lawton, J., 1977. Number of trophic levels in ecological communities. Nature 268, 329-331.

Porter, M.E., 2000. Location, competition, and economic development: Local clusters in a global economy. Economic development quarterly, 14, 15-34.

Rawles, 1999, A theory of justice. Belknap press, Cambridge Massachusetts.

Reilly, M., Willenbockel, D., 2010. Managing uncertainty: a review of food system scenario analysis and modelling. Philosophical transactions of the royal society $365,3049-3063$.

Sebag,M., 2014. A tour of Machine learning: an Al perspective. Al communications, IOS Press, 27(1), 11-23.

Sicard, M., Baudrit, C., Leclerc-Perlat, M.N., Wuillemin, P.H., Perrot, N., 2011. Expert knowledge integration to model complex food processes. Application on the camembert cheese ripening process. Expert Systems with Applications, 38(9), 11804-11812.

Sicard, M., Perrot, N., Reuillon, R., Mesmoudi, S., Alvarez, I., Martin, S. 2012. A viability approach to control food processes: Application to a Camembert cheese ripening process. Food Control, 23, 312-319.

Stoutemyer, D. R., 2013, Can the Eureqa Symbolic Regression Program, Computer Algebra, and Numerical Analysis Help Each Other? Notices of the AMS (60), 713-724.

Suppes, P., 2002. Representation and Invariance of Scientific Structures, University of chicago publications.

Surana, A., Kumara, S., Greaves, M., Nandini, C., Raghavan, U., 2013. Supply-chain networks: a complex adaptive systems perspective. International Journal of Production Research 43(20), 4235-4265.

Takagi, H., 2008. New topics from recent interactive evolutionary computation researches. In: KnowledgeBased Intelligent Information and Engineering Systems. p. 14.

Thompson, J., Scoones, I., 2009. Addressing the dynamics of agri-food systems: an emerging agenda for social science research. Environmental science \& policy 12, 386-397.

Tonda, A., Spritzer, A., and Lutton, E, 2014. Balancing User Interaction and Control in BNSL. In Artificial Evolution (pp. 211-223). Springer International Publishing.

Trystram, G., 2012. Modelling of food and food processes. Journal of Food Engineering 110, 269277. 
Uzzi, B., 1996. The sources and consequences of embeddedness for the economic performance of organizations: The network effect. American sociological review, 674-698.

960

961

962

963

964

965

966

967

968

969

970

971

972

973

974

\section{Figure captions}

976

977

978

979

980

981

982

983

984

985

986

987

988

989 20-32. doi:10.1093/nar/gku1105 redrawn from Miller et al., 2010

Van Coller, L., 1997. Automated techniques for the qualitative analysis of ecological models : Continuous models. Conservation Ecology 1 (1), 5.

Van Mil, H.G.J. , Foegeding, A.E. , Windhab, E.J. , Perrot, N., Van der Linden, E. (2014). A complex system approach to address world challenges in food and agriculture. Trends in Food Science and Technology, 40 (1),

Walker, B., Gunderson, L., Kinzig, A., Folke, K., Carpenter, S., Schultz, L., 2006. A handful of heuristics and some propositions for understanding resilience in social-ecological systems. Ecology and Society 11, 1-13.

Wei, W., Alvarez, I., Martin, S., 2013. Sustainability analysis: Viability concepts to consider transient and asymptotical dynamics in socio-ecological tourism-based systems. Ecological Modelling 251, 103-113.

Wodke, J.A.H, Alibés, A., Cozzuto, L., Hermoso, A., Yus, E., Lluch-Senar, M., et al., 2015. MyMpn: a database for the systems biology model organism Mycoplasma pneumoniae. Nucleic Acids Res. 2015;43: D618-D623.

Zwart, Sjoerd D., Ibo van de Poel, Harald van Mil, and Michiel Brumsen. 2006. A Network Approach for Distinguishing Ethical Issues in Research and Development. Science and Engineering Ethics 12 (4):663-684.

\section{Figure 1: Complex system approach inspired from the CS roadmap 2012-2020}

Figure 2: A viability kernel recalculated for the cheese ripening application described in (Sicard et al., 2012) (Mesmoudi et al., 2014). The First 8 days of the 12-days viability tube of the ripening process of Camembert Cheese are represented. The color shows the robustness (square distance to the boundary of the viability day-section) with blue points less robust than red ones. The target in black is reached in 12 days but at day 8 some robust states are already in the target.

Figure 3: Integrated assessment and policy-development process indicating key ingredients, flows, and interactions between analytical and participatory components of the process. Inspired and

Figure 4: Length scales in the manufacture and supply structured products.

Figure 5: Example of Functional classification of the metatranscriptome during surface-ripened cheese maturation (from Dugat-Bony et al., In press). 


\section{Table caption}

991 Table 1: A synthesis of methodologies and computing tools, already available or in development, for

992 sustainable food systems. For each point, we provide examples taken from subsection 4.3 , as this

993 case study addresses issues spanning all the considered elements.

994

995 
Table 1

\begin{tabular}{|c|c|c|c|c|}
\hline & & Partly realized & Reachable & To achieve \\
\hline $\begin{array}{c}\text { Step 1: } \\
\text { Systemic } \\
\text { analysis, or } \\
\text { 'painting the } \\
\text { picture' }\end{array}$ & $\begin{array}{l}\text { Computing } \\
\text { paradigms }\end{array}$ & $\begin{array}{l}\text { Ontologies and } \\
\text { conceptual graphs, } \\
\text { mathematical } \\
\text { descriptions } \\
\text { mediated by } \\
\text { cognitive science } \\
\text { approaches (Sicard } \\
\text { et al., 2011) }\end{array}$ & $\begin{array}{l}\text { Gathering human and } \\
\text { expert knowledge. This } \\
\text { step is sometimes } \\
\text { performed, but there is } \\
\text { no generic } \\
\text { methodology yet. } \\
\text { Fuzzy logic (Perrot, } \\
\text { 2006), qualitative } \\
\text { physics (Bousson et al., } \\
\text { 2000), mathematical } \\
\text { graphs (Baudrit, } \\
\text { Wuillemin \& Perrot, } \\
\text { 2013), cognitive } \\
\text { to link to mathematical } \\
\text { concepts (Mouzé- } \\
\text { sonce. Concepts from } \\
\text { cognitive science, } \\
\text { Amady, Raufaste, Prade }\end{array}$ & $\begin{array}{l}\text { Intelligent systems, } \\
\text { able to treat } \\
\text { different sources of } \\
\text { information into a } \\
\text { homogeneous } \\
\text { framework. }\end{array}$ \\
\hline
\end{tabular}


ACCEPTED MANUSCRIPT

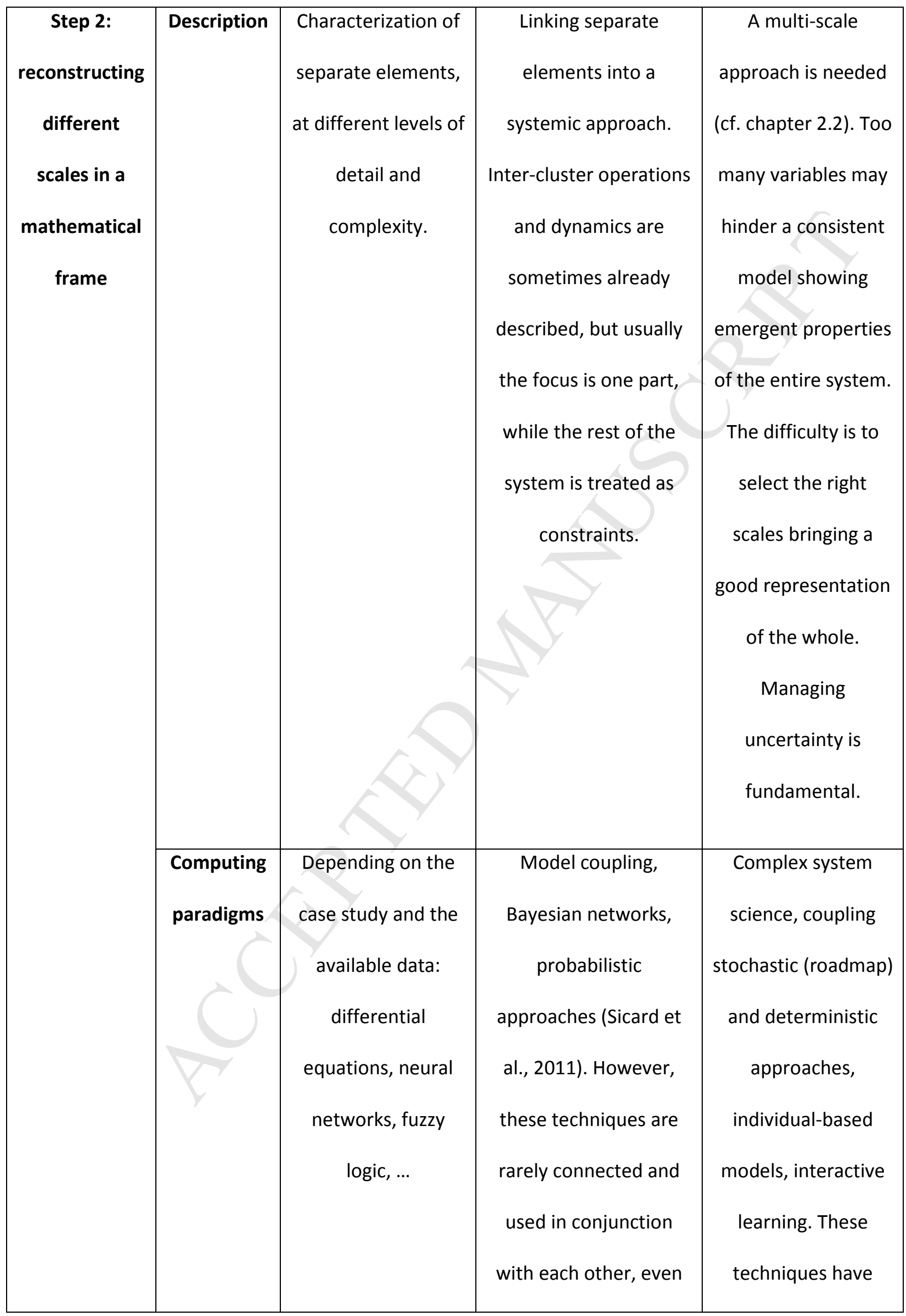




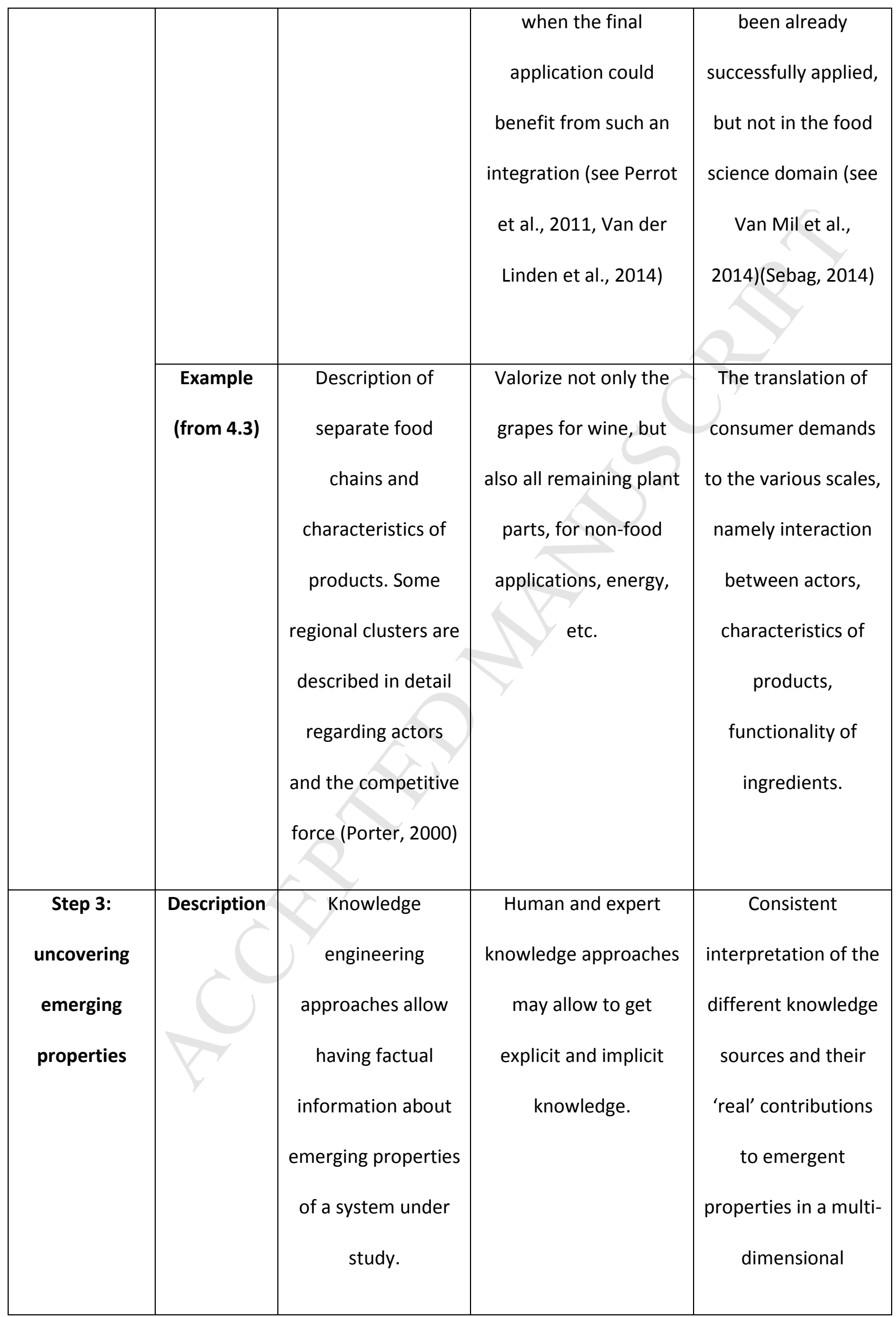




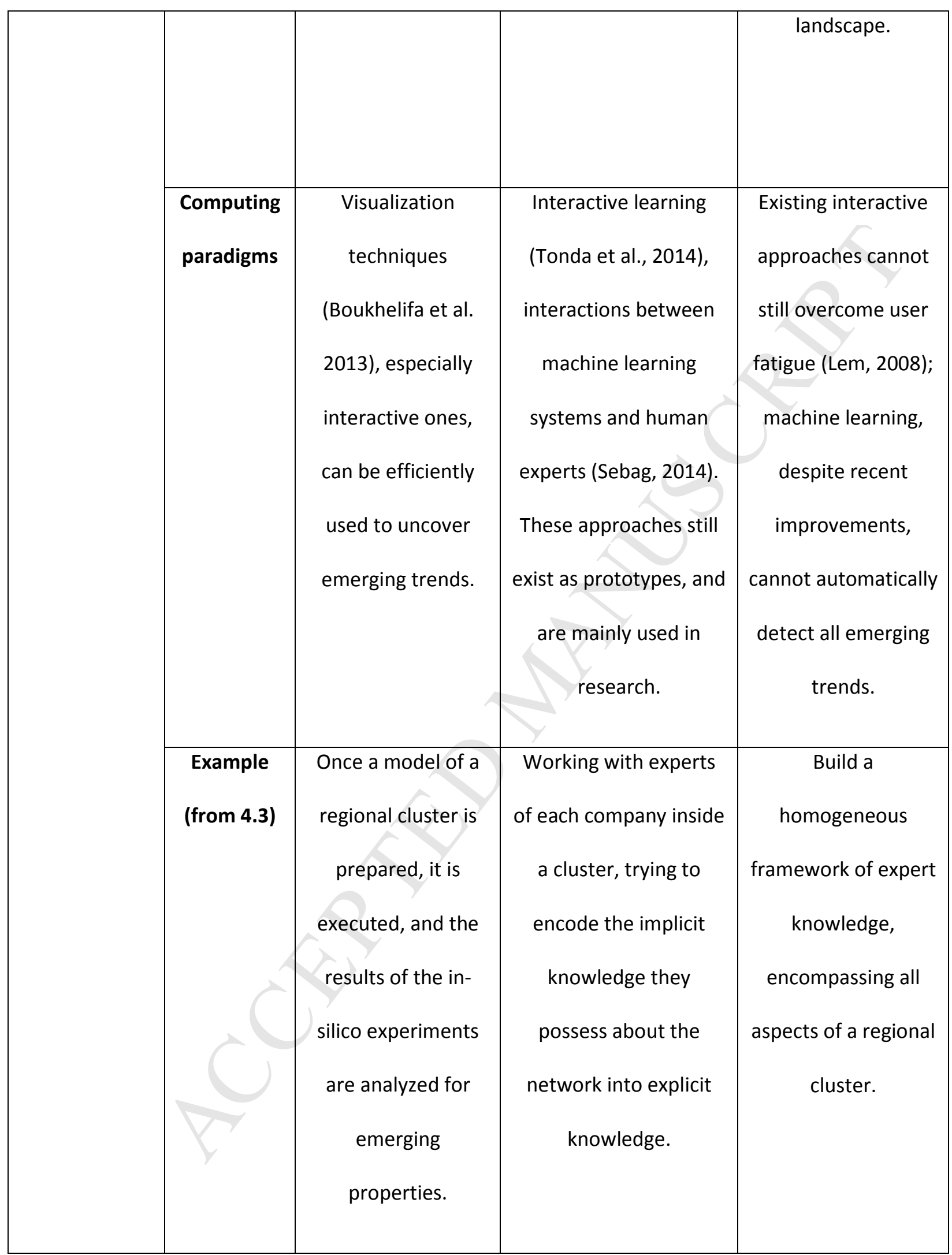


ACCEPTED MANUSCRIPT

\begin{tabular}{|c|c|c|c|c|}
\hline $\begin{array}{l}\text { Step 4: system } \\
\text { optimization } \\
\text { and resilience }\end{array}$ & Description & $\begin{array}{l}\text { The various actors } \\
\text { could be easily } \\
\text { identified including } \\
\text { their decisive power } \\
\text { at all scales and } \\
\text { their constraints } \\
\text { and decision } \\
\text { criteria. } \\
\text { Formalization of } \\
\text { their constraints } \\
\text { and choices is } \\
\text { possible. }\end{array}$ & $\begin{array}{l}\text { The necessity is to learn } \\
\text { from a large benchmark } \\
\text { of simulations in } \\
\text { interaction with the } \\
\text { experts. The expression } \\
\text { of the mathematical } \\
\text { function to optimize, } \\
\text { the tuning of the } \\
\text { algorithms are not } \\
\text { trivial (Sebag, 2014). }\end{array}$ & $\begin{array}{l}\text { The value of } \\
\text { optimization may be } \\
\text { rather complicated } \\
\text { to establish, because } \\
\text { the appropriate } \\
\text { definition of the } \\
\text { diverse } \\
\text { environmenty complex and } \\
\text { context would } \\
\text { require taking into } \\
\text { account feedback } \\
\text { and feedforward } \\
\text { effects. In practice, } \\
\text { these factors cannot } \\
\text { yet be practically } \\
\text { implemented, as the } \\
\text { non-linearity of the } \\
\text { ans increases. }\end{array}$ \\
\hline
\end{tabular}


ACCEPTED MANUSCRIPT

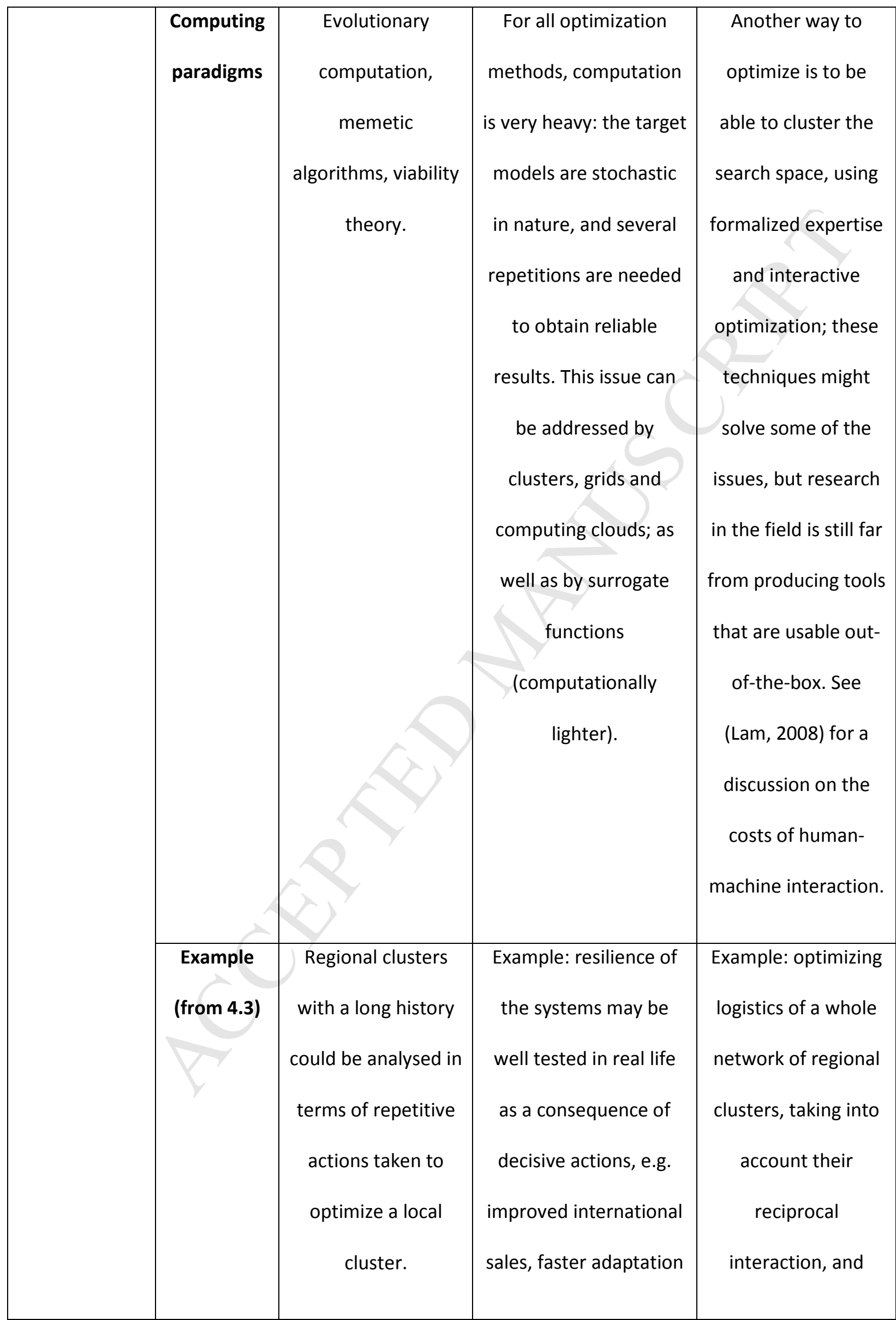




\begin{tabular}{|l|l|c|c|}
\hline & & to external changes by & their influence on \\
enterprises, ... & the environment \\
& & & and other existing \\
& & & structures. \\
\hline
\end{tabular}

Comment citer ce document :

Perrot, N., De Vries, H., Lutton, E., van Mil, H. G. J., Donner, M., Tonda, A., Martin, S. 


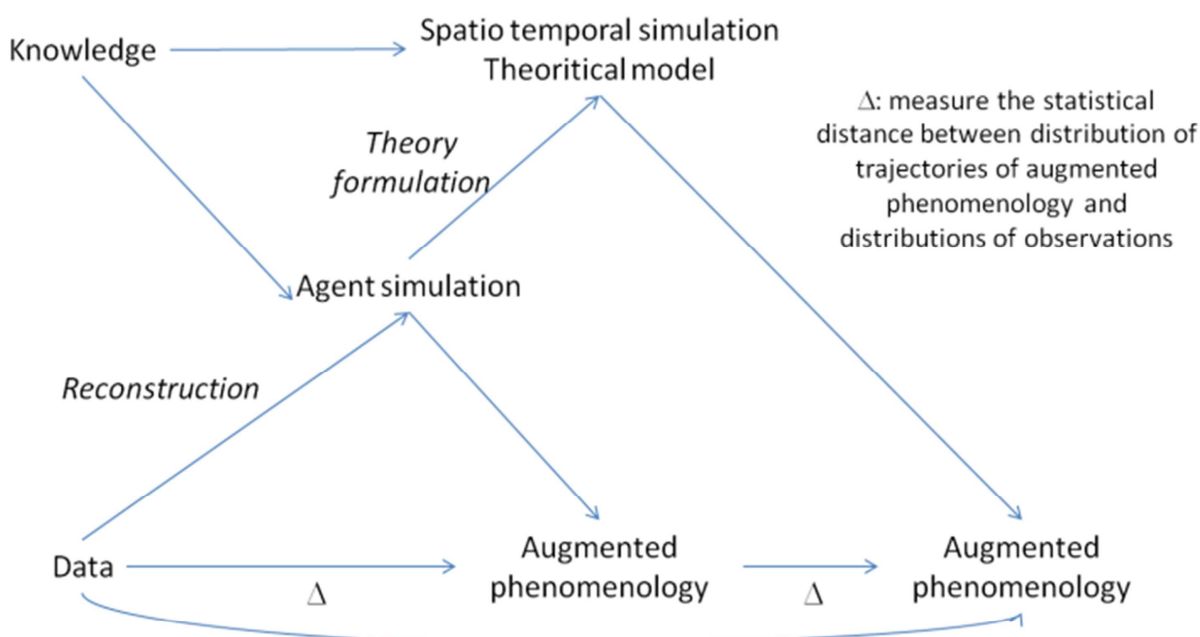

$\Delta$

Figure 1

Comment citer ce document :

Perrot, N., De Vries, H., Lutton, E., van Mil, H. G. J., Donner, M., Tonda, A., Martin, S. 


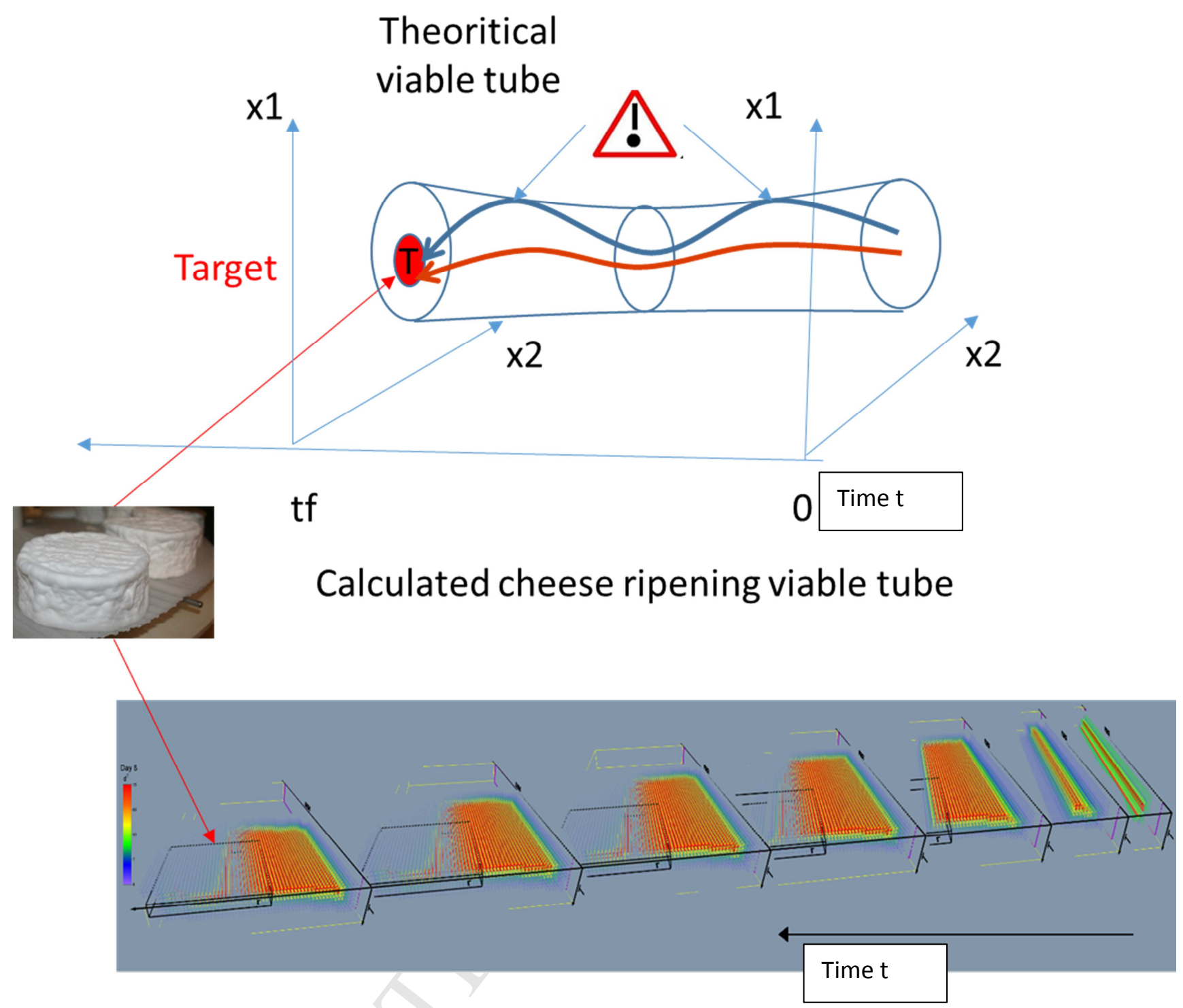

Figure 2 


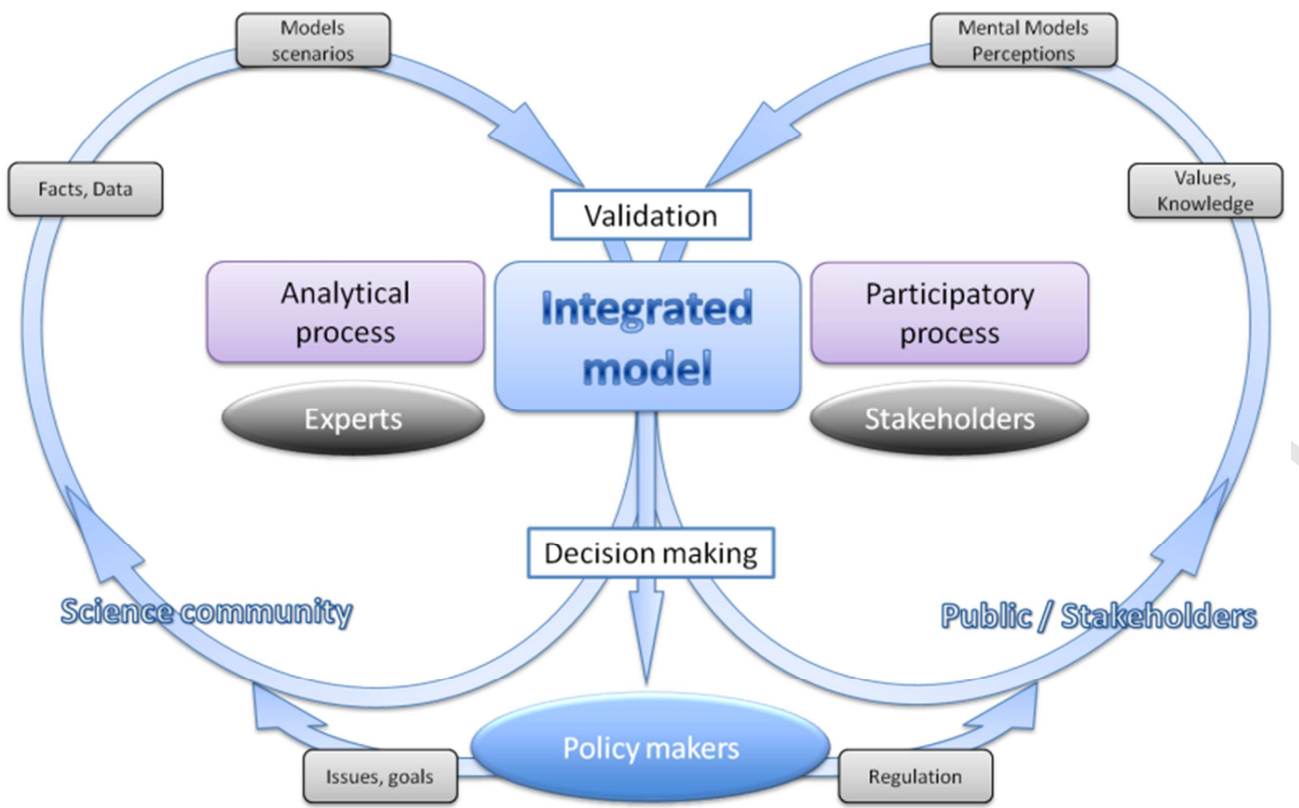

Figure 3

Comment citer ce document :

Perrot, N., De Vries, H., Lutton, E., van Mil, H. G. J., Donner, M., Tonda, A. Martin, S. 


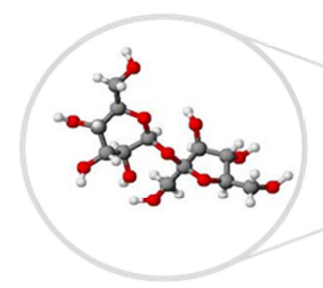

a - molecular level $0.1-100 \mathrm{~nm}$

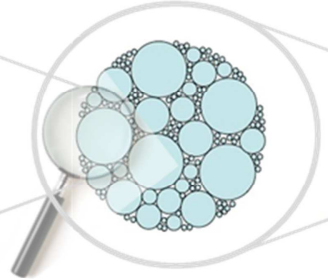

b- microstructure 1-1000 $\mu \mathrm{m}$

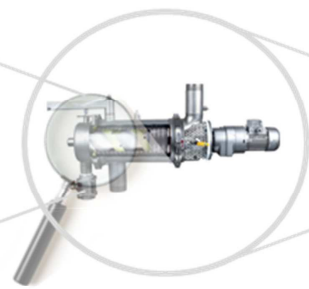

c- unit operations

$0.1-10 \mathrm{~m}$

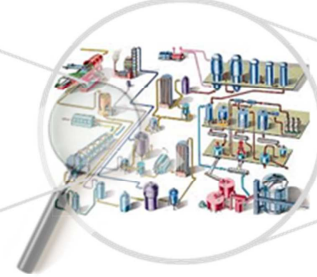

$\mathrm{d}$ - factory level $100-1000 \mathrm{~m}$

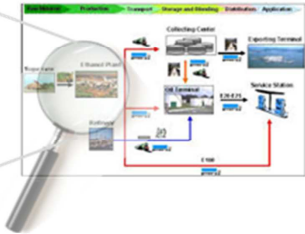

e - supply chain $10-100 \mathrm{~km}$

Figure 4 


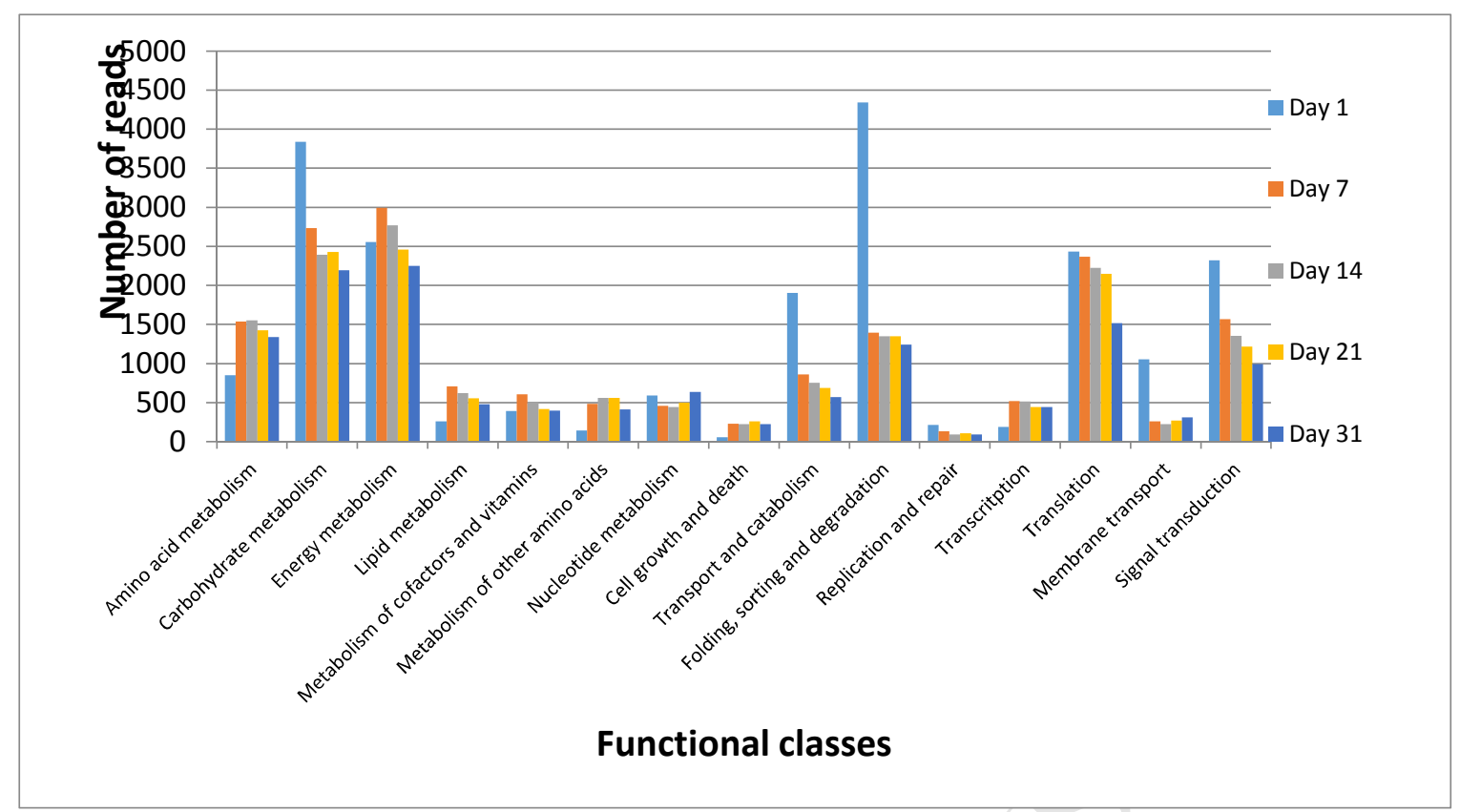

Figure 5 
Highlights :

The agri-food sector is one of the most important sectors of the industry

Dealing with sustainability issues in this sector, is a enormous and difficult challenge.

Here lies a huge opportunity at the frontier of agri-food and computing science.

New mathematical tools are proposed to address sustainability of food systems.

Key examples are developed. 